"A FEA e a USP respeitam os direitos autorais deste trabalho. Nós acreditamos que a melhor proteção contra o uso ilegítimo deste texto é a publicação online. Além de preservar o conteúdo motiva-nos oferecer à sociedade o conhecimento produzido no âmbito da universidade pública e dar publicidade ao esforço do pesquisador. Entretanto, caso não seja do interesse do autor manter o documento online, pedimos compreensão em relação à iniciativa e o contato pelo e-mail bibfea@usp.br para que possamos tomar as providências cabíveis (remoção da tese ou dissertação da BDTD)." 
Universidade de São Paulo

Faculdade de Economia, Administração e Contabilidade

Instituto de Matemática e Estatística

Mestrado Profissionalizante "Modelagem Matemática em Finanças"

\title{
Calibração Entrópica para Modelos de Taxa de Câmbio
}

\author{
Paulo Roberto Lagrotta
}

Dissertação apresentada a

Faculdade de Economia,

Contabilidade e Administração e ao

Instituto de Matemática e

Estatística da Universidade de São

Paulo para a obtenção do Título de

de Mestre.

Orientador: Prof. Dr. Pedro Paulo Schirmer

São Paulo

2003 


\section{Resumo}

A teoria da Informação nos ensina que a entropia é essencial para transmissão de informação. Considerando a eficiência informacional do mercado, assumimos que o preço de um determinado ativo objeto reflete toda informação que chega ao mercado e levando as distribuições de probabilidade de seus retornos serem ajustadas ao risco. Este trabalho aplica o tratamento entrópico para o mercado de taxa de câmbio brasileiro e sugere um modelo com probabilidades calibradas entropicamente a partir de contratos futuros de dólar que possa ser utilizado para a avaliação de estratégias de operações de opções de dólar permitindo detectar distorções entre os mercados de futuros e de opções de taxa de câmbio. 


\begin{abstract}
The Information theory teaches that entropy is fundamental to transmission of information. Considering the operational efficiency of price we have assumed that informational efficiency of market prices adjusts the distribution probabilities of return prices to a risk-neutral in an Arrow-Debreu economy. This work apply the entropic theory for the Brazilian FX market and suggest an entropic adjusted probabilities model using the the FX future contracts. This model can be used to evaluate the FX option strategies and analyze mismatches between FX future and FX Option contracts.
\end{abstract}


Dedico este trabalho a todos os meus grandes amigos. 


\section{Agradecimentos}

Ao meu orientador professor Dr. Pedro Paulo Schirmer; todos os professores do Instituto de Matemática da USP e da Faculdade de Economia e Administração da USP que contribuíram para a minha formação.

Aos membros da banca, Prof. Dr. José de Oliveira Siqueira e Prof. Dr. Rogério Rosenfeld.

À Erica Buna e à profa. Dra Constança T. Marcondes Cesar por mais do que caberia aqui.

À minha mãe Waldira Lagrotta.

A Ronaldo C. M. Lima, pelas discussões sobre física, economia e sobre tudo; mas principalmente pela amizade e pelo apoio.

Aos inúmeros amigos que fiz na FEA e no IFUSP.

Ao Banco ING pelo patrocínio financeiro. 


\section{Conteúdo}

1 Introdução 1

2 Entropia 4

2.1 Entropia e Finanças. . . . . . . . . . . . . . . . 4

2.2 Expressão para o Cálculo da Entropia - Caso Discreto . . . . . . . . . . . 6

2.2.1 Exemplos de cálculo de Entropia . . . . . . . . . . . . 7

2.2.1.1 Exemplo 1: Distribuição Uniforme . . . . . . . . . 7

2.2.1.2 Exemplo 2: Experimento de Bernoulli . . . . . . . 7

2.3 Propriedades para o Caso Discreto . . . . . . . . . . . . . . . . . 7

2.4 Uma Justificativa Intuitiva para a expressão da Entropia . . . . . . . . . . 8

2.5 Entropia Relativa . . . . . . . . . . . . . . . . 10

2.5.1 Exemplos de cálculo de Entropia Relativa . . . . . . . . . . . . 12

2.5.1.1 Entropia Relativa entre dois Experimentos de Bernoulli . . 13

2.6 Propriedades da Entropia Relativa . . . . . . . . . . . . . . . . 14

2.7 Minimização da Entropia Relativa Sujeita à Restrições . . . . . . . . . . 15

3 Mercado de Dólar no Brasil $\quad 18$

3.1 Mercado de Dólar Futuro no Brasil . . . . . . . . . . . . . . 18

3.1 .1 Relação entre Preços à Vista e Preços à Futuro . . . . . . . . . . . 19

3.1.2 Construção da Estrutura a Termo da taxa PRÉ . . . . . . . . . . . 21

3.1.3 Construção da Estrutura a Termo da taxa CUPOM . . . . . . . . . 22 
4 Processos Difusivos e Entropia 24

4.1 Processos Difusivos . . . . . . . . . . . . . . . . . 24

4.2 Simulação de Processos Difusivos através de Árvores Binomiais e Trinomiais 27 4.2 .1 Árvores Trinomiais . . . . . . . . . . . . . . . . . 30

4.3 Minimização da Entropia Relativa e o Dólar Futuro . . . . . . . . . . . . . 32

4.4 o modelo . . . . . . . . . . . . . . . . . . 33

5 Estratégias de Avaliações de Opções de Câmbio 37

5.1 Comportamento Histórico do Câmbio brasileiro . . . . . . . . . . . 37

5.2 Resultados Obtidos . . . . . . . . . . . . . . . . 41

5.3 Resumo dos resultados obtidos . . . . . . . . . . . . . . 54

6 Conclusão $\quad 56$

A Método para interpolação de taxa de juros 58

B Programas Utilizados para análise $\quad 61$

B.1 Programa Principal . . . . . . . . . . . . . . . 61

B.2 Programa de Minimização . . . . . . . . . . . . . . . 65

B.3 Programa que Calcula a Distribuição Calibrada Entropicamente . . . . . . 66

B.4 Programa que calcula a distribuição histórica . . . . . . . . . . . . 67 


\section{Capítulo 1}

\section{Introdução}

O conceito de entropia foi originalmente introduzido pela Física Termodinâmica e possuía a finalidade de determinar se um dado processo físico ocorria espontaneamente ou não. Entende-se como um processo Físico espontâneo um processo que não esta submetido a ação de eventos externos. Observou-se desde então que nos processos dinâmicos onde a energia era mantida constante a entropia aumentava. Isto sugeria a interpretação da entropia como uma medida de desordem.

Outra área da ciência que utiliza a idéia de entropia é da Teoria de Informação. Esta teoria nos ensina que a entropia é fundamental para a compressão e propagação das informações, sendo muito utilizada na Engenharia Elétrica, onde ela é usada como um critério para determinar a eficiência de armazenamento e transmissão de informações.

Modernas Teorias de Finanças ensinam que mercados desenvolvidos e competitivos armazenam e transmitem informações a respeito dos preços dos ativos com uma certa eficiência sugerindo que o preço do ativo objeto negociado reflete todas as informações e efeitos externos submetidos ao mercado.

Estudos recentes sugerem que a entropia é uma ferramenta estatística muito útil na determinação de probabilidades ajustadas ao risco a partir de preços observados no mercado, principalmente em mercados incompletos.

Defini-se como mercado completo um mercado onde podemos através de vários ativos 
objeto replicar o fluxo de pagamento de um portfolio para qualquer evento que possa ocorrer no futuro, caso contrário denominamos de mercado incompleto.

Em uma economia real o mercado é incompleto pois há inúmeras fontes de incertezas, cujos prêmios de risco são desconhecidos.

Ingersoll em 1987 demonstrou em seu trabalho que para mercados incompletos podemos obter várias medidas de Arrow-Debreu produzindo assim uma ambiguidade, uma vez que podemos utilizar diferentes distribuições de probabilidades para o apreçamento de um mesmo derivativo.

Dentre o conjunto de várias medidas de Arrow-Debreu possíveis o mercado provavelmente escolhe aquela de máxima entropia. No caso em que o investidor faz uso de uma informação a priori, o mercado atualiza esta distribuição de probabilidades de tal forma que a entropia relativa seja miníma impondo como restrição os preços vigentes de mercado (Gulko 1997).

A relação existente entre entropia e transmissão de informação sugere uma ligação entre preços negociados e Entropia, principalmente se levarmos em consideração que todas as informações disponíveis no mercado estão refletidas no preço do ativo.

Modernas teorias de finanças ensinam que mercados competitivos produzem e transmitem informações com uma certa eficiência.

Esta dissertação tenta combinar a idéia de mercado eficiente com o formalismo de entropia.

No primeiro capítulo será desenvolvido todo o formalismo matemático relacionado a entropia enquanto que o segundo capítulo será apresentada uma breve descrição do mercado de dólar e seus derivativos negociados no Brasil.

No terceiro capítulo será feita uma relação entre entropia e processos difusivos, sendo por último sugerido um modelo calibrado de maneira Entrópica para a avaliação de opções de dólar.

No quarto capítulo será efetuada a calibração e análise do modelo proposto no terceiro capítulo, sugerindo uma estratégia para operação de opções de dólar. 
No quinto e último capítulos serão abordadas as conclusões e as considerações finais do trabalho. 


\section{Capítulo 2}

\section{Entropia}

Este capítulo tem por finalidade apresentar o conceito de entropia e realizar sua ligação com finanças.

Será apresentado também o formalismo matemático necessário para a compreensão e cálculo da entropia com a apresentação de alguns exemplos teóricos.

Por último será apresentado o conceito de entropia relativa, tópico que será usado em capítulos posteriores para a construção do modelo de avaliação de opções.

\subsection{Entropia e Finanças}

Um grande número de estudos recentes, como Rubinstein(1994) e Avellaneda et al (1997), sugerem que as idéias de entropia e de volatilidade são ferramentas estatísticas úteis na determinação de distribuições de probabilidades ajustadas ao risco, a partir de preços de ativos e derivativos observados no mercado.

A teoria de Arbitragem proposta por Harrison-Kreps(1979) e Harrison-Pliska(1980) prêveem a existência de uma distribuição de probabilidades ajustada ao risco em uma economia de Arrow-Debreu, mas não fornece uma metodologia de como obter tal distribuição a partir de informações disponíveis no mercado, apenas assegura que todas as probabilidades contidas na distribuição são positivas e que medem um estado futuro do 
preço do respectivo ativo objeto. Além disso, mostram que em mercados completos esta medida é única, sustentando os preços de equilíbrio do mercado.

A construção de uma distribuição ajustada ao risco não apresenta grandes problemas em uma economia com mercado completo, dada a sua unicidade, mas produz ambiguidade em um mercado incompleto, onde várias distribuições podem serem compatíveis com os preços de equilíbrio, como foi demonstrado por Ingersoll em 1987.

Medidas empíricas de distribuições de probabilidades obtidas a partir de preços de mercado revelam as seguinte propriedades:

1. A forma da distribuição de probabilidades implícita dos retornos logarítmicos dos preços de mercado possuem uma forma de sino (Fig 2.1).

2. As volatilidades dos preços futuros obtidas a partir da distribuição ajustada ao risco são dificilmente diferentes da volatilidade do ativo objeto.

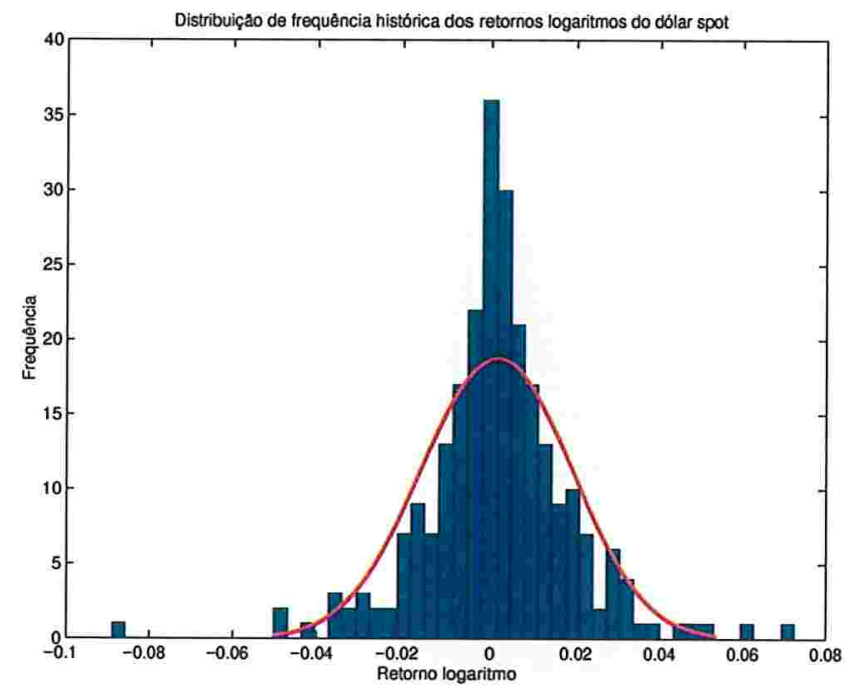

Figura 2.1: Histograma que evidência empiricamente a forma de sino de uma distribuição de probabilidades para a cotação do Dólar spot $\mathrm{R} \$ /$ USD. Para a geração deste histograma foram consideradas as cotações de fechamento entre 01 de Janeiro de 2002 a 31 de Dezembro de 2003 
Trabalhos recentes sugerem que a distribuição ajustada ao risco de preços futuros de ativos objetos maximizam a entropia condicionada as informações disponíveis no mercado. Podemos evidenciar esse efeito, por exemplo, quando a cotação do dólar é afetada pelo anúncio de novas medidas econômicas proposta pelo governo de um país.

A grande vantagem de se utilizar o conceito de entropia nos mercados financeiros é que este conceito fornece condições suficientes para a determinação de uma única distribuição ajustada ao risco, tanto em mercados completos como em incompletos, obedecendo todas a propriedades exigidas pela Teoria de Arbitragem, ou seja, todas as probabilidades positivas, e obedecendo a forma de sino, como sugerem as evidências empíricas.

O conceito de entropia também pode ser relacionado a eficiência de transmissão de novas informações que serão refletidas nos preços de mercado de um determinado ativo objeto. Quanto mais eficiente for a transmissão da informação maior será a incerteza coletiva do mercado sobre o próximo movimento do preço do ativo. Olhando a entropia como uma medida de incerteza, podemos dizer que para um mercado eficiente temos um estado de máxima entropia, sendo assim um parâmetro de determinação de um mercado eficiente.

\subsection{Expressão para o Cálculo da Entropia - Caso Dis- creto}

Nas seções seguintes introduziremos o formalismo matemático da entropia para o caso discreto.

A entropia de uma variável aleatória $X$ assumindo os valores discretos $x_{1}, \ldots, x_{n}$ e probabilidades $P\left(X=x_{i}\right)=p_{i}$ para $i=1, \ldots, n$, é definida como:

$$
h(X) \equiv h(p)=-\sum_{i=1}^{n} p_{i} \log p_{i}
$$




\subsubsection{Exemplos de cálculo de Entropia}

A seguir serão ilustrados alguns exemplos de cálculo da entropia para distribuições discretas.

\subsubsection{Exemplo 1: Distribuição Uniforme}

Seja $\Omega=\left(\omega_{1}, \ldots, \omega_{n}\right)$ com $n \in \mathbb{N}$ e suponha que sobre esse conjunto tenhamos uma distribuição uniforme $p(N)=\left(\frac{1}{N}, \ldots, \frac{1}{N}\right)$. Calculando a entropia dessa distribuição temos:

$$
h(p(N))=-\sum_{i=1}^{n} p_{i} \log p_{i}=-\sum_{i=1}^{n} \frac{1}{N} \log \frac{1}{N}=\log N
$$

Observando o resultado acima nota-se que a entropia é uma função crescente de $N$ e que $\lim _{N \rightarrow \infty} h(p(N))=\infty$. Portanto para uma distribuição uniforme, quanto maior for o número de estados da natureza $N$, maior será a incerteza em relação ao resultado do processo, pois todos os possíveis resultados possuem a mesma probabilidade de ocorrência.

\subsubsection{Exemplo 2: Experimento de Bernoulli}

Para um experimento de Bernoulli com probabilidade de sucesso $p$, a entropia é igual a:

$$
h((p, 1-p))=p \log p+(1-p) \log (1-p)
$$

Observe que para $p=0$ ou $p=1$ (eventos certos), a entropia se anula, ou seja, não há aleatoriedade no processo. Outra característica é de que a entropia atinge o valor máximo para $p=\frac{1}{2}$ determinando um alto grau de incerteza e impossibilitando realizar alguma previsão.

\subsection{Propriedades para o Caso Discreto}

A seguir temos algumas propriedades da entropia para o caso discreto. 
Teorema 1 As seguintes afirmações são verdadeiras:

1. $h(X) \geq 0$;

2. $h(X)=0$ se, e somente se, $p_{i}=1$ para algum estado $i=1,2, \ldots$

3. Se a variável aleatória $X$ assume um número finito de valores, digamos $n$ valores, então sua entropia atinge o máximo exatamente quando os $p_{i}$ 's são todos idênticos. Em particular, $h(X) \leq \log n$.

Quando um evento é certo $\left(p_{i}=1\right.$ ou $\left.p_{i}=0\right)$ a entropia é miníma, ou seja, não há mais nenhuma informação disponível ou, em outras palavras, não há incerteza. Por outro lado quando todos os eventos do processo tem a mesma probabilidade de ocorrer, a entropia é máxima, ou seja, não é possível extrair nenhuma informação a partir da distribuição de probabilidades.

\subsection{Uma Justificativa Intuitiva para a expressão da Entropia}

O valor de qualquer produto esta relacionado com a sua oferta e demanda no mercado. Quanto mais escasso ou demandado for o objeto, mais caro ele se torna e vice-versa (lei da oferta e demanda). A oferta ou a demanda pode ser definida como uma medida de probabilidade $P$ de se encontrar disponível no mercado um determinado produto (ex. commodity). Esta probabilidade está definida em um espaço de probabilidade.

Podemos então dizer que o valor de um produto satisfaz as seguintes propriedades:

1. O valor de dois produtos deve ser maior que o valor de cada produto individualmente.

2. Se dois produtos não são substituíveis, ou parcialmente substituíveis um pelo outro, então o valor total pelo dois produtos será a soma do valor individual de cada produto.

3. O valor de um produto nunca é negativo. 
A única função matemática que satisfaz todas as propriedades acima possui a forma:

$$
V(P)=-\log _{b} P
$$

sendo $b$ é uma constante positiva.

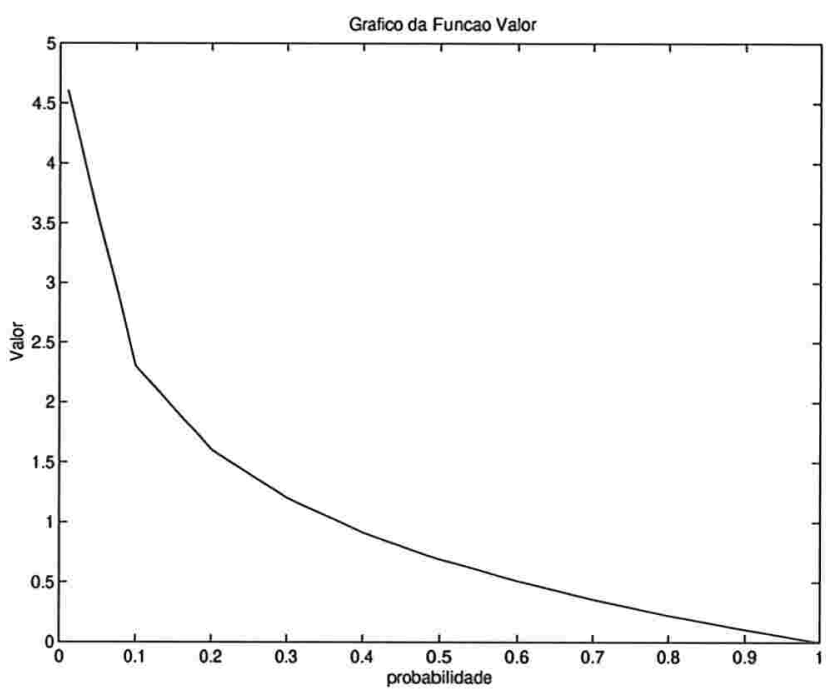

Figura 2.2: Gráfico da Função Valor.

Podemos observar na (Fig. 2.2) que para $P=1$ temos $-\log P=0$, indicando que o valor de produtos abundantes será igual a zero enquanto que produtos $\operatorname{raros}(P \approx 0)$ possuem um valor de mercado alto.

Considere agora, para o desenvolvimento do raciocínio, um espaço $\Omega$ de eventos pertencentes a um processo aleatório particionado por um número finito de eventos $E_{i}$ mutuamente exclusivos e com probabilidades associadas $p_{i}$ conhecidas.

Considere agora a variável aleatória

$$
X=-\log p
$$

definida sobre o espaço $\Omega$ descrito acima.

Para cada evento $E_{i}$ há um valor $x_{i}$ correspondente dado por: 


$$
x_{i}=-\log P\left[E_{i}\right]=-\log p_{i}
$$

A quantidade $-\log p_{i}$ é freqüentemente chamada de quantidade de auto-informação associada ao evento $E_{i}$. Note que a partir deste ponto começamos a fazer a ligação entre entropia e informação.

Define-se a quantidade de auto-informação associada a um evento como:

$$
I\left(E_{i}\right)=-\log p_{i}
$$

note que $I\left(E_{i}\right)$ é sempre maior que zero, pois por definição $p_{i} \geq 0$.

$$
I\left(E_{i}\right)=-\log p_{i} \geq 0
$$

Usando esta idéia podemos dizer que a quantidade de informação média do sistema pode ser definida como:

$$
H(X)=\overline{I\left(E_{i}\right)}=-\sum_{i=1}^{n} p_{i} \log p_{i}
$$

A quantidade de informação média também é conhecida como entropia.

Portanto, se $-\log p_{i}$ indica a medida de incerteza associada ao evento $E_{i}$, então $H(X)$ irá representar a média ou a expectativa de incerteza associada ao processo.

Note que a partir deste momento temos uma expressão matemática capaz de relacionar a quantidade de incerteza relativa a uma informação atribuída a um evento.

\subsection{Entropia Relativa}

A entropia relativa, também conhecida como Informação ou divergência de KullbackLeibler, será importante porque nos dará a idéia de quão discrepantes são duas distribuições de probabilidade. A entropia relativa não é uma métrica, portanto não podemos dizer que estamos obtendo um tipo de distância entre duas distribuições, mas em certas circunstâncias pode-se mostrar que a entropia relativa possui todas as propriedades de uma distância. Esta noção será utilizada no decorrer deste trabalho. 
Usando a idéia que a expressão (2.7) está associada à uma quantidade de informação, como descrito na sessão anterior, somos levados intuitivamente a dizer que a diferença da quantidade de informação contida entre duas distribuições de probabilidades pode ser definida como:

$$
\log q_{i}-\log p_{i}
$$

Em média a diferença de quantidade de informação será dada por:

$$
\sum_{i=1}^{N} q_{i}\left(\log q_{i}-\log p_{i}\right)=\sum_{i=1}^{N} q_{i} \log \frac{q_{i}}{p_{i}}
$$

Definição 1 Sejam $P$ e $Q$ duas medidas de probabilidade quaisquer definidas sobre o mesmo espaço. Define-se então como entropia relativa, $D(Q, P)$, entre $P$ e $Q$ como:

$$
D(Q, P)=\left\{\begin{aligned}
\int \log \left(\frac{d Q}{d P}\right) d Q & , \text { se } Q \ll P \\
\infty & , \text { caso contrario }
\end{aligned}\right.
$$

Para o caso discreto temos:

$$
D(q, p)=\sum_{i=1}^{N} q_{i} \ln \frac{q_{i}}{p_{i}}
$$

onde $p=\left(p_{1}, . ., p_{N}\right)$ e $q=\left(q_{1}, . ., q_{n}\right)$.

A definição para o caso discreto coincide com a idéia intuitiva descrita pela expressão (2.11).

Agora vamos analisar duas medidas discretas de probabilidades denotadas por $P=$ $\left(p_{1}, \ldots, p_{2}\right)$ e $Q=\left(q_{1}, \ldots, q_{2}\right)$. Supondo que para qualquer valor de $p_{i}$ vale a condição $p_{i}>0$ podemos escrever a expressão para a entropia relativa como sendo:

$$
D(Q, P)=\sum_{i} q_{i} \ln \frac{q_{i}}{p_{i}}
$$

Expandindo o termo $\ln \frac{q_{i}}{p_{i}}$ ao redor de 1 na equação 2.14, temos que:

$$
\ln \frac{q_{i}}{p_{i}}=\ln \left(1+\frac{q_{i}-p_{i}}{p_{i}}\right)=\frac{q_{i}-p_{i}}{p_{i}}+O\left(\left(\frac{q_{i}-p_{i}}{p_{i}}\right)^{2}\right)
$$


Desprezando os termos de segunda ordem da expansão acima e lembrando que $\sum_{i} p_{i}=$ $1 \mathrm{e} \sum_{i} q_{i}=1$, podemos reescrever a equação 2.14 da seguinte forma:

$$
\begin{aligned}
D(Q, P) \simeq \sum_{i} q_{i}\left(\frac{q_{i}-p_{i}}{p_{i}}\right) & =\sum_{i} \frac{q_{i}^{2}-p_{i} q_{i}}{p_{i}}+\sum_{i} p_{i}-\sum_{i} q_{i} \\
& =\sum_{i} \frac{\left(q_{i}-p_{i}\right)^{2}}{p_{i}} \\
& =\chi^{2}(Q, P)
\end{aligned}
$$

Ou seja, a entropia pode ser aproximada por:

$$
D(Q, P) \approx \sum_{i} \frac{\left(q_{i}-p_{i}\right)^{2}}{p_{i}}=\chi^{2}(Q, P)
$$

onde $\chi^{2}(Q, P)$ é a medida de aderência relativa.

A expressão acima possibilita calcular a entropia relativa entre dois conjuntos de probabilidades se os valores de $p_{i}$ e $q_{i}$ são muito próximos. Neste ponto gostaríamos de adiantar que distribuições de probabilidades históricas para diferentes dias da cotação do dólar no Brasil possuem valores muito próximos.

Analisando a equação (2.16) notamos que para um dado estado onde estão determinados o conjunto de probabilidades $P$ e $Q$ se minimizarmos a entropia relativa estaremos deformando a distribuição de referência concedendo maior aderência aos estados mais prováveis e menos aderências aos estados menos prováveis. Este efeito esta representado na Figura (2.3) através de duas distribuições Gaussianas Contínuas. Note que quanto menor for o valor da probabilidade $p_{i}$ mais ele contribuirá para o somatório da expressão da entropia relativa.

\subsubsection{Exemplos de cálculo de Entropia Relativa}

A seguir temos alguns exemplos de cálculo para entropia relativa. 


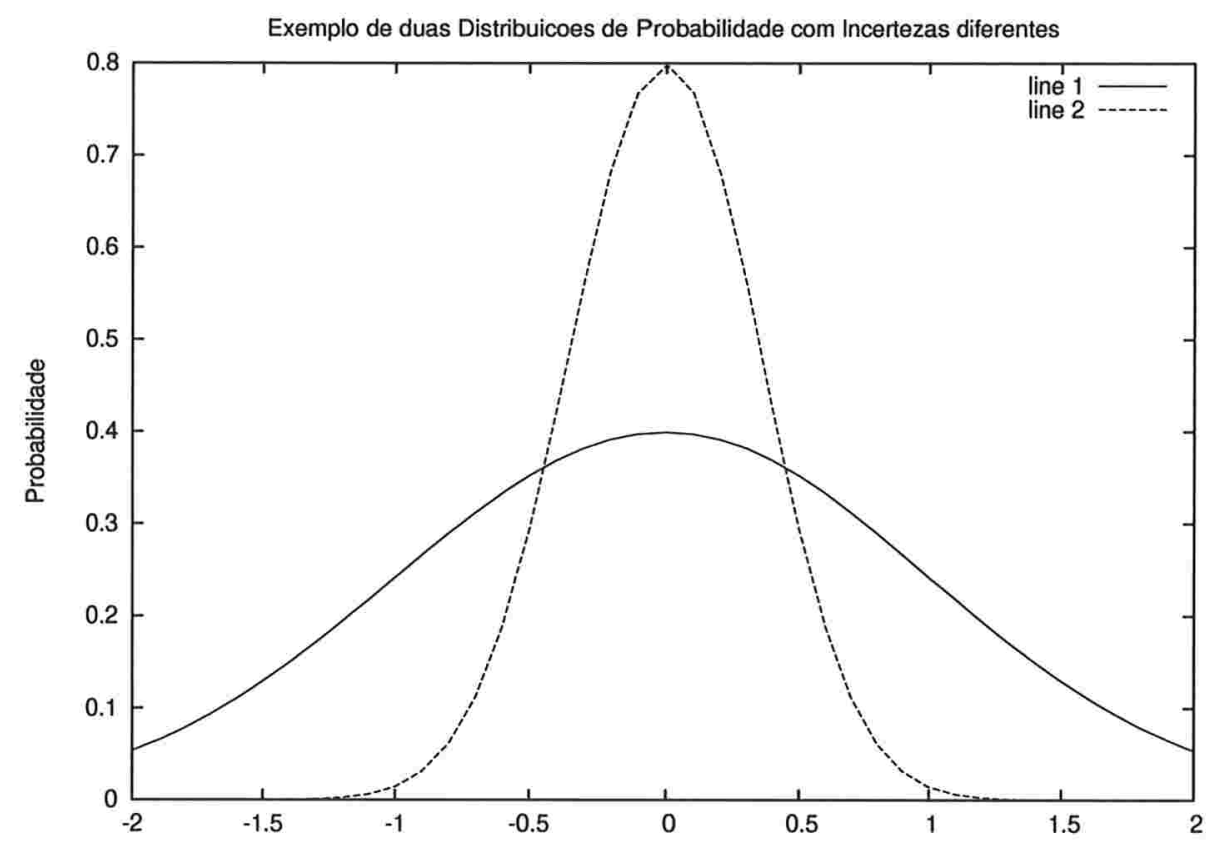

Figura 2.3: Exemplo de duas distribuições de Probabilidades Contínuas e Teóricas com incertezas diferentes. Note que a curva com maior incerteza possui caudas mais pesadas, enquanto a com menos incerteza possui um núcleo com probabilidades mais significativas.

\subsubsection{Entropia Relativa entre dois Experimentos de Bernoulli}

Seja $\Omega=\{0,1\}$ e considere as seguintes distribuições de probabilidade sobre $\Omega$.

$$
q=(1-r, r)
$$

$\mathrm{e}$

$$
p=(1-s, s)
$$

Então,

$$
D(p, q)=\left(\log \frac{1-r}{1-s}\right)(1-r)+\left(\log \frac{r}{s}\right) r
$$

enquanto que, 


$$
D(q, p)=\left(\log \frac{1-s}{1-r}\right)(1-s)+\left(\log \frac{s}{r}\right) s
$$

Tomando $r=\frac{1}{2}$ e $s=\frac{1}{4}$ temos:

$$
D(p, q)=\left(\log \frac{\frac{1}{2}}{\frac{3}{4}}\right) \frac{1}{2}+\left(\log \frac{\frac{1}{2}}{\frac{1}{4}}\right) \frac{1}{2}
$$

$\mathrm{e}$

$$
D(q, p)=\left(\log \frac{\frac{3}{4}}{\frac{1}{2}}\right) \frac{3}{4}+\left(\log \frac{\frac{1}{4}}{\frac{1}{2}}\right) \frac{1}{4}
$$

Observa-se que $D(p, q) \neq D(q, p)$, de modo que a entropia relativa não é, em geral, simétrica. Economicamente podemos interpretar que nem toda a informação a respeito de um determinado ativo objeto é inteiramente compartilhada representando uma assimetria da informação.

\subsection{Propriedades da Entropia Relativa}

A seguir temos as propriedades da Entropia Relativa.

Teorema 2 Sejam $P$ e $Q$ duas medidas de probabilidades sobre um mesmo espaço $\Omega$. Então $D(P, Q) \geq 0$, sendo que $D(P, Q)$ somente, e somente se, será igual a 0 se $P=Q$

Teorema 3 Dadas duas distribuições $P=\left(p_{1}, . ., p_{n}\right)$ e $Q=\left(q_{1}, \ldots, q_{n}\right)$, então:

$$
h(q)=-D(p, q)-\sum_{i=1}^{n} q_{i} \ln p_{i}
$$

Teorema 4 A entropia relativa $D(P, Q)$ é convexa em $(P, Q)$

Teorema 5 A entropia relativa $D(P, Q)$ é estritamente convexa em $Q$

Estes dois últimos teoremas serão importantes para a próxima sessão, onde iremos minimizar a Entropia Relativa sujeita a restrições, pois garantem que $D(Q, P)$ é convexa e conseqüentemente possui apenas um minímo global. 


\subsection{Minimização da Entropia Relativa Sujeita à Res- trições}

Nesta sessão iremos determinar o ponto de minímo da função entropia relativa submetida a restrições. Neste primeiro momento não nos preocuparemos em justificar os vínculos a qual a função entropia relativa está sujeita, ficando para sessões posteriores a interpretação econômica.

Dadas duas distribuições de probabilidade $P=\left(p_{1}, \ldots, p_{n}\right)$ e $Q=\left(q_{1}, \ldots, q_{n}\right)$, a entropia relativa de $Q$ em relação a $P$ será dada por:

$$
D(Q, P)=\sum_{i=1}^{n} q_{i} \log \frac{q_{i}}{p_{i}}
$$

Vamos supor agora que a expressão acima está sujeita às seguintes restrições:

$$
\left\{\begin{array}{r}
\sum_{i=1}^{n} q_{i}=1 \\
\sum_{i=1}^{n} \xi_{i} q_{i}=F
\end{array}\right.
$$

onde $F$ é um valor constante e $\xi=\left(\xi_{1}, \ldots, \xi_{n}\right)$.

Portanto as equações de vínculo serão dadas por:

$$
\begin{aligned}
& \phi_{1}\left(q_{i}\right)=\sum_{i=1}^{n} q_{i}-1=0 \\
& \phi_{2}\left(q_{i}\right)=\sum_{i=1}^{n} \xi_{i} q_{i}-F=0
\end{aligned}
$$

O ponto crítico da função $D(p, q)$ será determinado pelo método de Multiplicadores de Lagrange. Equacionando temos:

$$
d D(p, q)+\lambda_{1} d \phi_{1}+\lambda_{2} d \phi_{2}=0
$$

Realizando as derivações acima chegamos ao seguinte sistema de equações: 


$$
\begin{aligned}
& \frac{\partial D(p, q)}{\partial q_{i}} d q_{i}+\lambda_{1} \frac{\partial \phi_{1}}{\partial q_{i}} d q_{i}+\lambda_{2} \frac{\partial \phi_{2}}{\partial q_{i}} d q_{i}=0 \\
& \frac{\partial D(p, q)}{\partial p_{i}} d p_{i}+\lambda_{1} \frac{\partial \phi_{1}}{\partial p_{i}} d p_{i}+\lambda_{2} \frac{\partial \phi_{2}}{\partial p_{i}} d p_{i}=0
\end{aligned}
$$

A partir da equação (2.29) temos que:

$$
\begin{aligned}
& \ln \frac{q_{i}}{p_{i}}+1+\lambda_{1}+\lambda_{2} \xi_{i}=0 \\
& q_{i}=p_{i} e^{-1-\lambda_{1}-\lambda_{2} \xi_{i}}
\end{aligned}
$$

Substituindo a equação (2.31) em (2.26) temos que:

$$
\begin{aligned}
& \sum_{i=1}^{n} p_{i} e^{-1-\lambda_{1}-\lambda_{2} \xi_{i}}=1 \\
& e^{-1-\lambda_{1}} \sum_{i=1}^{n} p_{i} e^{-\lambda_{2} \xi_{i}}=1 \\
& \lambda_{1}=-1-\ln \left(\frac{1}{\sum_{i=1}^{n} p_{i} e^{-\lambda_{2} \xi_{i}}}\right)
\end{aligned}
$$

Substituindo a expressão de $\lambda_{1}$ obtido acima na equação (2.31) obtemos:

$$
q_{i}=\frac{e^{-\lambda_{2} \xi_{i}}}{\sum_{i=1}^{n} p_{i} e^{-\lambda_{2} \xi_{i}}} p_{i}
$$

Analisando a equação (2.33) notamos que não é nada mais que uma normalização do conjunto de probabilidade $P$.

O valor de $\lambda_{2}$ é finalmente calculado substituindo os valores de $q_{i}$ obtidos a partir da equação (2.33) na equação (2.27). Então a equação fica sendo:

$$
\sum_{i=1}^{n} \xi_{i} \frac{e^{-\lambda_{2} \xi_{i}}}{\sum_{i=1}^{n} p_{i} e^{-\lambda_{2} \xi_{i}}} p_{i}-F=0
$$

Para obtermos as probabilidades $Q=\left(q_{1}, \ldots, q_{n}\right)$ que minimizam a entropia relativa basta encontrarmos o valor de $\lambda_{2}$ que minimiza a expressão (2.34). O valor de $\lambda_{2}$ pode ser obtido através de algoritmos numéricos de minimização. 


\section{Gráfico de Comparação entre Probabiliades Históricas e Calibradas Entropicamente}

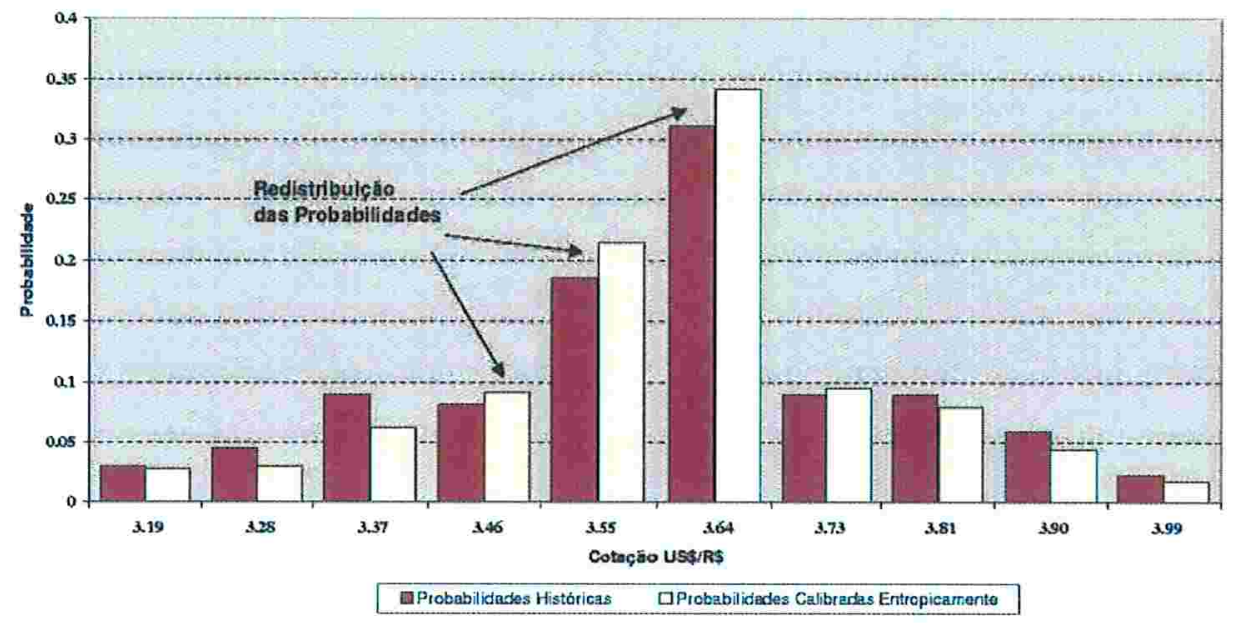

Figura 2.4: Exemplo de redistribuição das probabilidades através da Minimização da entropia relativa. Note que as probabilidades da cauda da distribuição histórica foram diminuídas e as probabilidades centrais foram acrescidas

Uma vez encontrado o valor de $\lambda_{2}$ que minimiza a Entropia Relativa, basta substituí-lo na expressão (2.33) para obtermos o conjunto de probabilidade $Q$ calibrado entropicamente.

Gostaria de ressaltar que recaímos num problema de minimização onde podemos ter mais de um minímo que satisfaz a equação (2.34), mas pelos teoremas anteriores temos a garantia que a função da entropia relativa é estritamente convexa e possui apenas um mínimo. 


\section{Capítulo 3}

\section{Mercado de Dólar no Brasil}

Neste capítulo serão apresentadas as características do mercado de dólar no Brasil e de seus derivativos. Também será analisada a expressão que calcula o valor do dólar Futuro para qualquer instante de tempo, fato que será utilizado mais adiante na elaboração do modelo de avaliação de opções de câmbio.

\subsection{Mercado de Dólar Futuro no Brasil}

O instrumento derivativo Dólar Comercial futuro negociado na Bolsa de Valores e Mercadoria de São Paulo (BM\&F) tem a principal finalidade de servir como proteção contra riscos da variação cambial, seja em operações cambiais comerciais, seja em operações financeiras.

O objeto do contrato é o Dólar Americano para entrega pronta (também chamado de dólar spot) e o tamanho de cada contrato é de USD $\$ 50.000,00$.

A cotação é dada em Reais por USD $\$ 1.000,00$ (Reais/USD $\$ 1.000,00$ ), portanto a apregoação será a taxa de câmbio (R\$/USD\$) multiplicada por mil.

\section{Exemplo:}

Se a taxa de câmbio vigente for R\$/USD\$ for 2,93 a cotação para o contrato de dólar futuro negociada na BM\&F poderá ser 2.930,721. 
Os vencimentos dos contratos ocorrem sempre no primeiro dia útil de cada mês, sendo portanto o último dia útil do mês anterior ao mês de vencimento do contrato o último dia de negociação.

A taxa de liquidação do contrato se dá pela taxa PTAX800 divulgada diariamente pelo Banco Central do Brasil. Gostaríamos de salientar que a liquidação não se dá pela cotação de fechamento do dólar de pronta entrega (spot) que difere da taxa PTAX800.

A taxa PTAX800 é uma taxa média ponderada pelo volume negociado pelo mercado que é calculada e divulgada pelo Banco Central do Brasil.

Para o nosso estudo este efeito de liquidação pela taxa PTAX não tem relevância e sempre iremos nos referir ao dólar spot, uma vez que esse efeito só possui relevância no último dia de negociação do contrato, caso que não analisaremos, e também porque sua liquidez (volume de contratos negociados) é muito baixa.

Em relação a liquidez dos contratos de dólar futuro, notamos que possui uma maior concentração no primeiro mês de vencimento, diminuindo para o segundo mês de vencimento e terminando com pouca liquidez para o terceiro mês. Do quarto mês em diante são raras as negociações. Neste estudo, vamos considerar os futuros até o terceiro mês de vencimento, onde consideramos que está concentrada a maior parte da liquidez.

\subsubsection{Relação entre Preços à Vista e Preços à Futuro}

Quando observamos a cotação do dólar spot e a do dólar futuro, notamos que tais preços diferem um do outro. Esta diferença é atribuída à uma série de motivos.

Como se sabe, os contratos futuros podem ser negociados para vários meses de vencimento futuros e teoricamente tais preços carregam um prêmio sobre os preços à vista.

Este prêmio espelha o custo de carregar uma posição comprada ou vendida na moeda até a data de liquidação do contrato.

Para compreender melhor a idéia acima vamos considerar a seguinte situação:

Uma carteira A possui um contrato futuro em Reais cujo montante em Reais no instante $t$ é dado por $F e^{-r(T-t)}$, onde $r$ é a taxa com que conseguimos aplicar os Reais, 
também chamada de taxa doméstica ou taxa PRÉ, $T$ é a data de vencimento e $t$ e o instante atual.

Vamos considerar agora uma outra carteira B que possui um contrato futuro em dólares cujo valor no instante $t$ dado por $e^{-r_{f}(T-t)}$, onde $r_{f}$ é a taxa com que conseguimos aplicar os dólares também conhecida como taxa CUPOM.

Supondo que o volume financeiro das duas carteiras são iguais, que a cotação de Reais por Dólares possui um valor $S$. Para não ocorrer arbitragem e desconsiderando todas as taxas de transação devemos observar a seguinte igualdade satisfeita:

$$
F e^{-P R E(T-t)}=S e^{-C U P O M(T-t)} \Rightarrow F=S e^{(P R E-C U P O M)(T-t)}
$$

A expressão acima é utilizada para calcular o valor do preço do contrato de dólar futuro quando as taxas de juros estão expressas na forma continuamente composta.

Atualmente o mercado financeiro brasileiro negocia as taxas de juros expressas no padrão exponencial com base $252^{1}$ dias úteis. A expressão 3.1 deve sofrer alguns ajustes para se calcular o preço do contrato de dólar futuro utilizando-se as taxas negociadas no mercado brasileiro. Fazendo as conversões das taxas a expressão acima fica da seguinte forma:

$$
F=\frac{S(1+P R E)^{\frac{(T-t)}{252}}}{(1+C U P O M)^{\frac{(T-t)}{252}}}
$$

A relação acima é conhecida como Relação de Paridade de Taxa. Podemos notar pela expressão (3.1) que quanto mais perto do vencimento estivermos, mais perto do valor do dólar spot estará a cotação do dólar futuro. Este efeito é conhecido como estreitamento da base e pode ser observado na Figura (3.1).

Outro fato importante que devemos chamar a atenção e que em posse das taxas pré e cupom podemos através da expressão (3.1) calcular o valor do Dólar Futuro para qualquer

\footnotetext{
${ }^{1} \mathrm{~A}$ relação entre taxas continuamente composta e exponencial 252 dias úteis se dá através da expressão $e^{\frac{r t}{n}}=(1+t x)^{\frac{n}{252}} \Rightarrow r=\frac{t}{252} \ln (1+t x)$; onde $r$ é a taxa continuamente composta e $t x$ é a taxa composta com base 252 dias úteis.
} 


\section{Estreitamento da base}

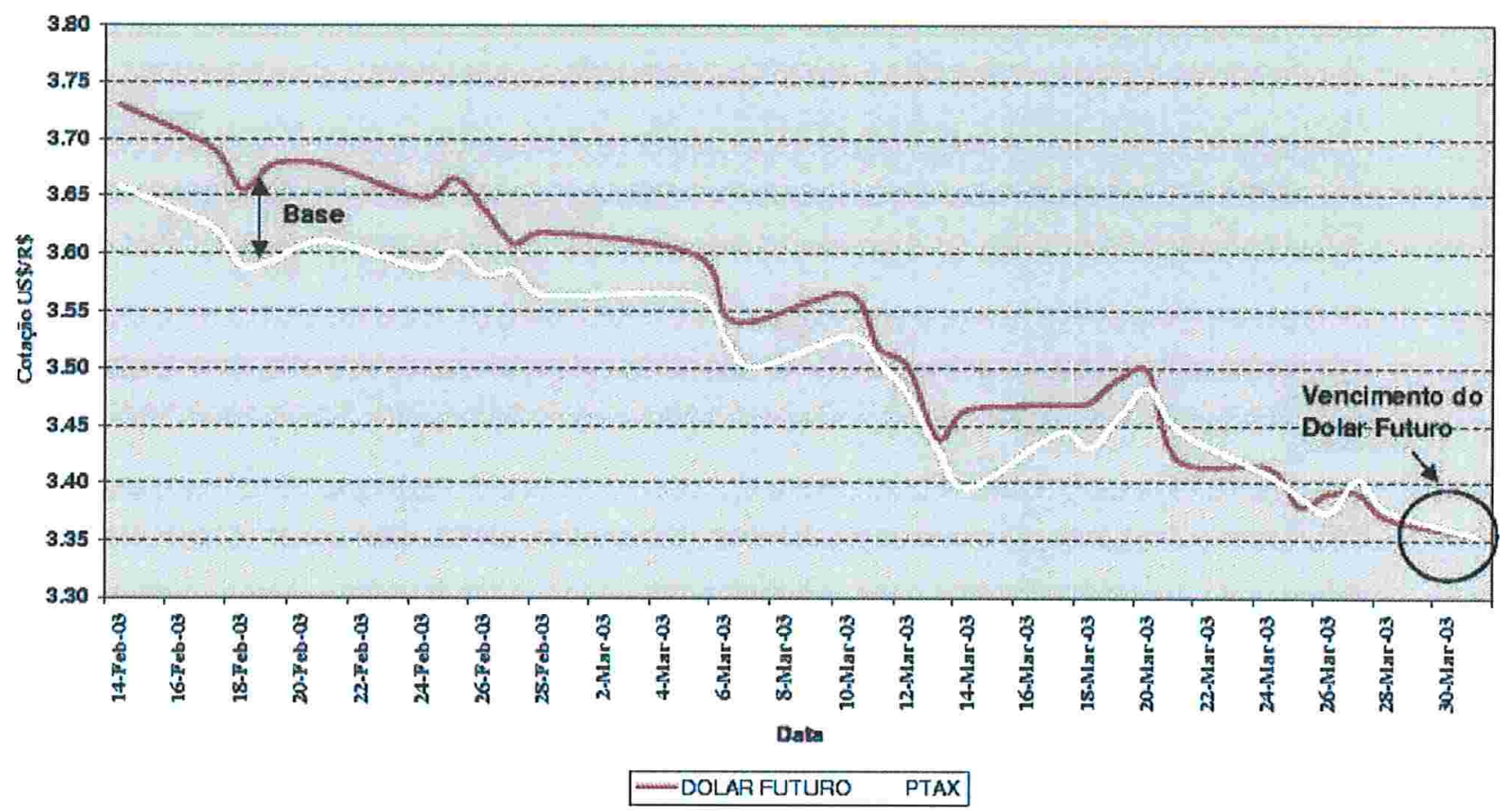

Figura 3.1: Gráfico que mostra o estreitamento da base entre o dólar spot e o dólar Futuro na data de vencimento do contrato de dólar Futuro.

instante de tempo futuro desde que conheçamos o valor de cotação do dólar SPOT.

\subsubsection{Construção da Estrutura a Termo da taxa PRÉ}

A Estrutura a Termo da Taxa Pré e obtida a partir dos Contratos Futuros de Depósitos Inter-financeiros de um Dia (DI), também conhecidos como contratos de DI, negociados pela BM\&F.

$\mathrm{O}$ valor negociado de contrato de DI, também conhecido como PU, corresponde a $\mathrm{R} \$ 100.000,00$ descontado pela taxa de juro efetiva entre o instante de negociação e o vencimento do contrato. O vencimento dos contratos sempre ocorrem no último dia útil de cada mês, sendo que são negociados contratos com vencimento entre os quatro primeiros meses subseqüentes ao mês que a operação foi realizada, e a partir daí, os meses que se 
caracterizam como inicio de trimestre.

Portanto a taxa Pré anualizada, base 252 dias úteis, pode ser calculada como:

$$
P R E_{i}=\left(\frac{100.000}{P U_{i}}\right)^{\frac{252}{n_{i}}}
$$

onde $i$ corresponde ao mês de vencimento do contrato Futuro, $P U_{i}$ corresponde ao último valor negociado do contrato com vencimento em $i$ e $n_{i}$ corresponde ao número de dias úteis compreendidos entre o instante da última negociação e o vencimento do contrato Futuro.

Para obter taxas de juro entre dias que o contrato Futuro de DI não é negociado utilizamos um método de interpolação de taxas de juro.

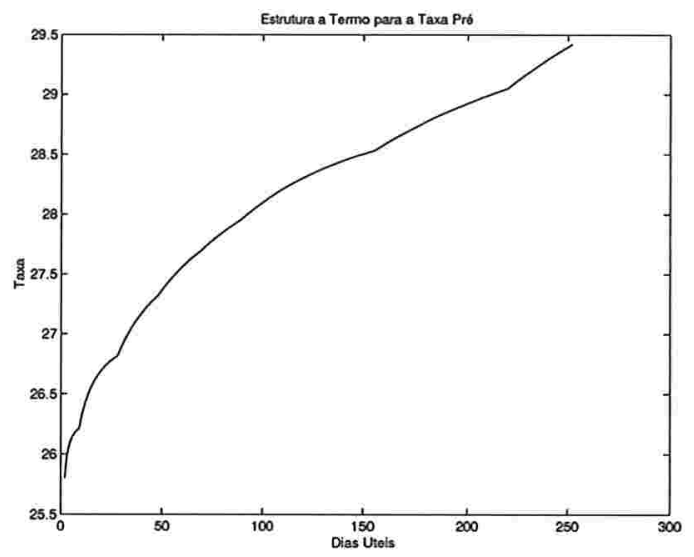

Figura 3.2: Estrutura a termo para a Taxa Pré. Esta estrutura foi construída com dados de fechamento dos contratos Futuros de DI do dia 25 de Maio de 2003.

\subsubsection{Construção da Estrutura a Termo da taxa CUPOM}

A obtenção da estrutura a termo da taxa de juro Cupom é obtida a partir da taxa Pré calculada na sessão anterior, do contrato de Dólar Futuro e do contrato Futuro de Cupom Cambial, também conhecido como FRA.

A taxa Cupom para o primeiro dia do primeiro mês de vencimento é obtida através da equação (3.2), pois isolando a taxa Cupom temos: 


$$
C U P O M=\frac{S}{F}(1+P R E)-1
$$

onde $F$ é o último valor negociado do contrato de Dólar Futuro, $S$ é o último valor negociado do Dólar Spot e PRE é a taxa Pré obtida na seção anterior.

A taxa Cupom para os demais meses é obtida através dos contratos FRA. Os contratos Futuros de FRA correspondem à taxa Cupom implícita entre o primeiro mês a partir da data de negociação e o mês de vencimento do contrato. Portanto, para os demais meses a taxa Cupom pode ser calculada da seguinte forma:

$$
C U P O M_{i}=C U P O M\left(1+F R A_{i}\right)
$$

onde $C U P O M$ é a taxa obtida pela expressão (3.4) e $F R A_{i}$ é a última taxa de negociação do contrato Futuro de FRA com vencimento no mês $i$.

Para se obter a taxa cupom nos demais dias onde o contrato Futuro de Dólar ou de FRA não são negociados utiliza-se o mesmo método de interpolação explicado para a taxa pré que esta demonstrado no Apêndice $A$.

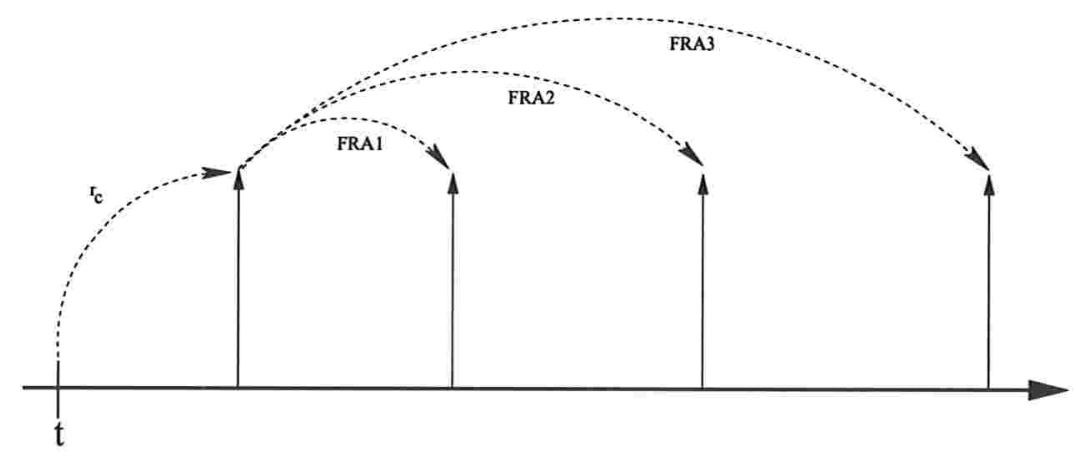

Figura 3.3: Esquema que auxilia na compreensão da obtenção da estrutura a termo da taxa cupom. 


\section{Capítulo 4}

\section{Processos Difusivos e Entropia}

Uma das maneiras mais difundidas na literatura para modelar a evolução temporal da cotação de um ativo objeto é considerando que o mesmo possui um comportamento igual ao de um movimento Browniano geométrico, também conhecido por processo difusivo.

Uma das maneiras possíveis de se simular um processo difusivo é através de árvore binomiais e trinomiais.

Este capítulo encontra-se dividido em três partes. Na primeira delas é feita a relação entre processos difusivos e Entropia. Na segunda serão apresentados modelos que nos permitem construir árvores trinomiais capazes de simular processos difusivos.

Por último será sugerido um modelo de árvore trinomial calibrado entropicamente.

\subsection{Processos Difusivos}

Iremos analisar nesta seção a entropia relativa para medidas de preços do dólar Futuro contra Real (USD/BRL).

Considerando duas medidas de probabilidades $P$ e $Q$ definidas no espaço de caminhos contínuos, temos: 


$$
\begin{aligned}
& \frac{d S_{t}^{P}}{S_{t}}=\sigma_{t}^{P} d Z_{t}^{P}+\mu_{t}^{P} d t \quad \text { comprobabilidade } P \text { de ocorrer } \\
& \frac{d S_{t}^{Q}}{S_{t}}=\sigma_{t}^{Q} d Z_{t}^{Q}+\mu_{t}^{Q} d t \quad \text { com probabilidade } Q \text { de ocorrer }
\end{aligned}
$$

A intenção do trabalho neste ponto é o de encontrar valores para $\sigma_{t}^{P}$ e $\sigma_{t}^{P}$ para cada instante de tempo no intervalo de tempo compreendido entre o instante atual até uma data pré estabelecida de tal forma que possamos construir uma estrutura a termo da volatilidade. A intenção de obtermos uma estrutura a termo de volatilidade será melhor entendida mais adiante.

Note que para as expressões acima se $\sigma_{t}^{P}=\sigma_{t}^{Q}=\sigma_{t}$, o cálculo da entropia relativa pode ser feito usando o Teorema de Girsanov.

Fazendo os cálculos temos:

$$
\varepsilon(Q, P)=\frac{1}{2} E^{Q} \int_{0}^{T}\left(\frac{\mu_{t}^{P}-\mu_{t}^{Q}}{\sigma_{t}}\right)^{2} d t
$$

De fato, definindo $\lambda_{t}$ como:

$$
\lambda_{t}=\frac{\mu_{t}^{P}-\mu_{t}^{Q}}{\sigma_{t}} \Rightarrow \mu_{t}^{P}=\mu_{t}^{Q}+\lambda_{t} \sigma_{t}
$$

Substituindo temos:

$$
\begin{aligned}
\frac{d S_{t}^{P}}{S_{t}} & =\sigma_{t}^{P} d Z_{t}^{P}+\left(\mu_{t}^{Q}+\lambda_{t} \sigma_{t}\right) d t \\
& =\sigma_{t}^{Q}\left(d Z_{t}^{Q}+\lambda_{t} d t\right)+\mu_{t}^{Q} d t
\end{aligned}
$$

Pelo Teorema de Girsanov temos:

$$
\frac{d Q}{d P}=e^{\int_{0}^{t} \frac{\lambda_{S}^{2}}{2} d s+\int_{0}^{t} \lambda d Z_{t}^{Q}}
$$

Substituindo a equação (4.7) na expressão da Entropia Relativa temos: 


$$
\begin{aligned}
\varepsilon(Q, P) & =E^{Q}\left[\ln \left(\frac{d Q}{d P}\right)\right] \\
& =E^{Q}\left[\int_{0}^{t} \frac{\lambda^{2}}{2} d s+\int_{0}^{t} \lambda d z_{t}^{Q}\right] \\
& =\frac{1}{2}\left[\int_{0}^{t}\left(\frac{\mu^{P}-\mu^{Q}}{\sigma}\right)^{2} d s\right]+E^{Q}\left[\int_{0}^{t} \lambda d Z_{t}^{Q}\right]
\end{aligned}
$$

Como $E^{Q}\left[\int_{0}^{t} \lambda d z_{t}^{Q}\right]=0$, podemos escrever a equação acima como:

$$
D(Q, P)=\frac{1}{2}\left[\int_{0}^{t}\left(\frac{\mu^{P}-\mu^{Q}}{\sigma}\right)^{2} d s\right]
$$

Portanto para calibrarmos a curva de volatilidade devemos considerar processos onde as volatilidades são diferentes. Para o caso contínuo, a entropia relativa será igual a $+\infty$ devido $P$ e $Q$ serem mutuamente singulares. Para o caso discreto não temos esse problema.

Consideremos agora duas medidas discretas de probabilidades $P$ e $Q$ definidas em um mesmo espaço.

$$
\Omega=\left\{S_{0}, S_{1}, \ldots, S_{n}\right\}
$$

A probabilidade $\mathrm{P}$ que um determinado caminho possa ocorrer será escrito como:

$$
\prod_{n=0}^{N} \pi_{n}^{P}
$$

onde $\pi_{n}^{P}$ é a probabilidade condicional dado o conjunto de informações conhecidas até o instante $n$ de que o preço $S_{n+1}$ irá ocorrer no instante $n+1$.

Fazendo a mesma analogia para o conjunto de probabilidades $Q$ podemos escrever a expressão da Entropia Relativa como:

$$
\begin{aligned}
D(Q, P) & =\sum_{\text {sobre todos caminhos }}\left(\prod_{n=0}^{N-1} \pi_{n}^{Q}\right) \ln \left(\frac{\prod_{n=0}^{N-1} \pi_{n}^{Q}}{\prod_{n=0}^{N-1} \pi_{n}^{P}}\right)= \\
& =E^{Q}\left[\sum \ln \left(\frac{\pi^{Q}}{\pi^{P}}\right)\right]
\end{aligned}
$$


A expressão acima mostra que a entropia relativa é obtida pela soma das entropias relativas ao longo de cada caminho ponderado pela probabilidade $Q$.

A idéia acima será utilizada mais adiante quando formos simular o processo difusivo através de árvores trinomiais e a calibrarmos entropicamente.

\subsection{Simulação de Processos Difusivos através de Árvores Binomiais e Trinomiais}

O modelo de árvores binomiais proposto inicialmente por Cox, Ross e Rubistein tinha como objetivo avaliar o apreçamento de derivativos considerando movimentos discretos do preço do ativo objeto (S) desde o instante inicial até o seu vencimento.

O primeiro modelo proposto foi de uma árvore binomial, onde o intervalo de tempo entre o instante inicial e o vencimento do derivativo era divido em um número de pequenos intervalos de tempo $\left(\Delta_{t}\right)$. O esquema de uma árvore binomial de apenas um período esta mostrado na Figura (4.1).

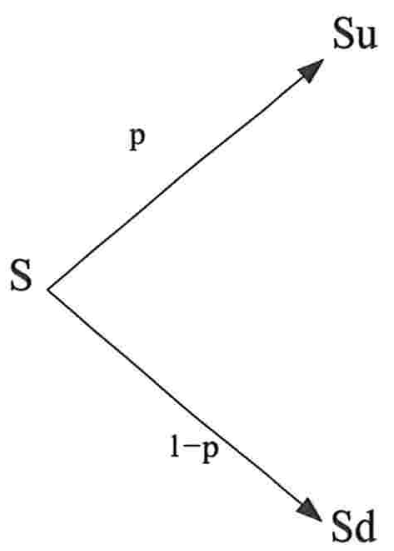

Figura 4.1: Exemplo de Árvore Binária de um período. 
Observe que o ativo objeto pode assumir apenas dois valores, onde $S u$ é um movimento ascendente do preço do ativo objeto, $S d$ é um movimento descendente. A probabilidade de termos um movimento ascendente do preço esta representado por $p$ onde $u$ e $d$ são fatores multiplicadores de $S$ que resultam nos dois valores possíveis que $S$ pode assumir, onde $u>1$ e $s<1$.

Note que a cada intervalo de tempo $\Delta t$ há três parâmetros a serem definidos $(p, S u . S d)$, que são os dois preços possíveis e a probabilidade de um movimento ascendente do preço.

Considerando que o processo binário descrito acima é também um processo ajustado ao risco, podemos dizer que o retorno esperado para cada intervalo de tempo deve ser igual a taxa livre de risco correspondente. Portanto temos a seguinte relação:

$$
\begin{aligned}
S e^{r \Delta t} & =S u p+S d(1-p) \\
e^{r \Delta t} & =u p+(1-p) d
\end{aligned}
$$

Sabemos também que a variância de um processo log-normal é dada por:

$$
S^{2} e^{2 r \Delta t}\left(e^{\sigma^{2} \Delta t}-1\right)
$$

Sabendo que expressão geral para o cálculo da variância é dada por:

$$
\operatorname{Var}(S)=E\left[S^{2}\right]-E[S]^{2}
$$

Podemos relacionar as expressões (4.14) e (4.15) tal que:

$$
\begin{aligned}
E\left[S^{2}\right]-E[S]^{2} & =p(S u)^{2}+(1-p)(S d)^{2}+[S u p+(1-p) S d]^{2} \\
& =p(S u)^{2}+(1-p)(S d)^{2}
\end{aligned}
$$

Igualando as expressões (4.15) e (4.17) temos:

$$
\begin{aligned}
S^{2} e^{2 r \Delta_{t}}\left(e^{\sigma^{2} \Delta_{t}}-1\right) & =p(S u)^{2}+(1-p)(S d)^{2} \\
e^{2 r \Delta_{t}}\left(e^{\sigma^{2} \Delta_{t}}-1\right) & =p u^{2}+(1-p) d^{2}
\end{aligned}
$$


Cox, Ross e Rubinstein sugerem em seu trabalho que os valores de $u$ e $d$ devem se relacionar da seguinte forma:

$$
u=\frac{1}{d}
$$

A relação para $u$ e $d$ proposta acima faz com que a árvore binomial seja simétrica em relação ao preço do ativo objeto no instante inicial, ou seja, seja simétrica em relação à $S$.

Note que temos três variáveis $(u, d, p)$ e três equações a serem determinadas. Temos assim um problema bem definido e com solução analítica.

Resolvendo o sistema de equações acima chegamos as relações:

$$
\left\{\begin{array}{c}
p=\frac{e^{r \Delta t}-d}{u-d} \\
u=e^{\sigma \sqrt{\Delta t}} \\
d=e^{-\sigma \sqrt{\Delta t}}
\end{array}\right.
$$

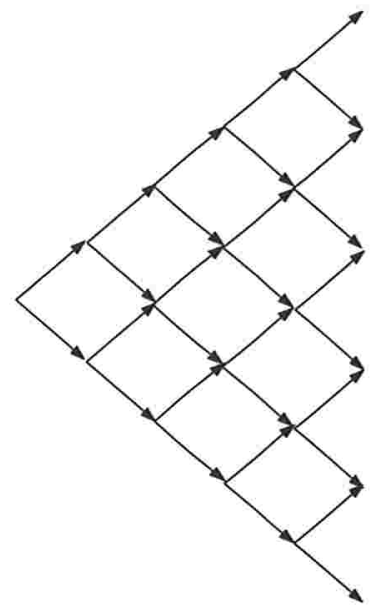

Figura 4.2: Exemplo de árvore binomial recombinante com vários períodos.

Note que para o processo de uma árvore binomial temos todos os parâmetros conhecidos e uma única solução para cada nó. 


\subsection{1 Árvores Trinomiais}

Alternativamente às árvores binomiais, podemos considerar também as chamadas árvores trinomiais, utilizadas para a avaliação de derivativos e para representar o movimento discreto do preço de ativos. A idéia assemelha-se à da árvore binomial mas ao invés do ativo objeto poder assumir dois valores diferentes para cada intervalo de tempo $\Delta t$ pode assumir três valores. A figura (4.3) representa este tipo de árvore para um período.

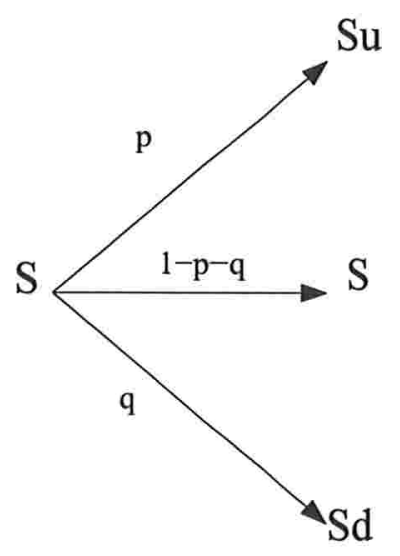

Figura 4.3: Exemplo de árvore trinomial para um período, onde $p$ e $q$ são respectivamente as probabilidades do ativo objeto obter um preço maior ou menor em relação ao instante atual.

Os valores $S u$ e $S d$ possuem uma probabilidade $p$ e $q$ de ocorrerem respectivamente e conseqüentemente $S$ (o preço do ativo objeto não se modifica) possui uma probabilidade $(1-p-q)$ de ocorrência.

Note que no final de cada intervalo de tempo $\Delta t$ há quatro parâmetros que são desconhecidos $(u, d, p, q)$, duas probabilidades e dois preços.

Uma solução para este tipo de problema é recombinar dois períodos de uma árvore binomial. Como mostrado na figura abaixo: 


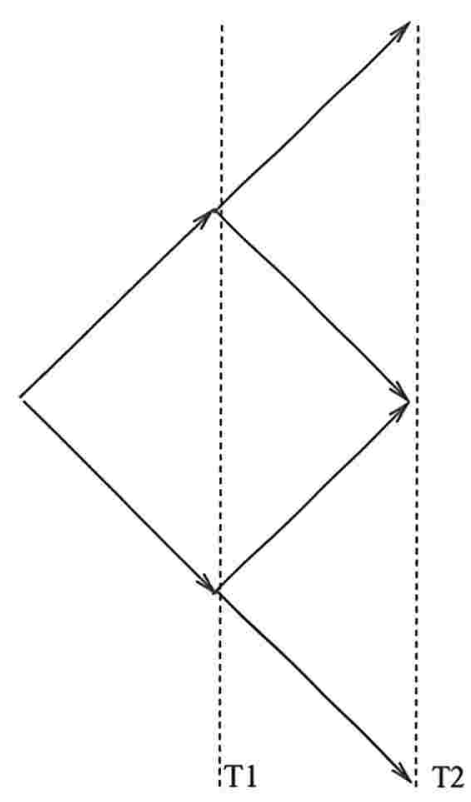

Figura 4.4: Exemplo de árvore trinomial recombinante para 1 período. Note que podemos obter este tipo de árvore recombinando dois períodos de uma árvore binomial

Em uma árvore trinomial recombinante com volatilidade constante temos, em geral os preços da seguinte forma:

$$
\left\{\begin{array}{r}
S_{u}=S e^{\sigma \sqrt{2 \Delta_{t}}} \\
S_{m}=S \\
S_{d}=S e^{-\sigma \sqrt{2 \Delta_{t}}}
\end{array}\right.
$$

onde $\sigma$ é a volatilidade. O resultado acima fica fácil de ser compreendido se analisarmos o resultado obtido para uma árvore binomial. Note que os valores de $S_{u}$ e $S_{d}$ nada mais são que o resultado de dois períodos de uma árvore binomial. 


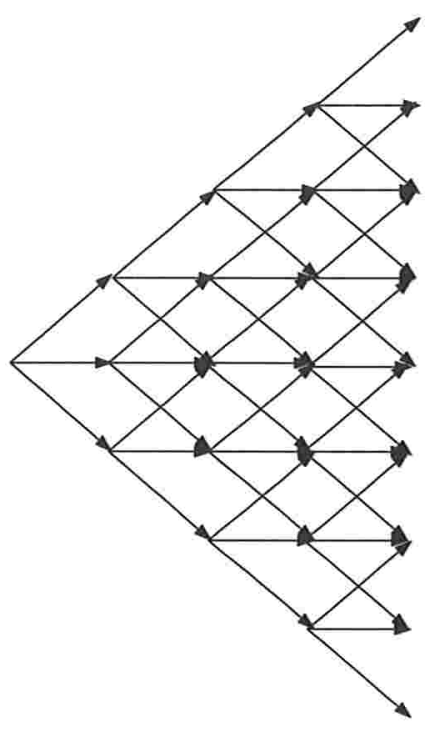

Figura 4.5: Exemplo de árvore trinomial recombinante para vários períodos.

\subsection{Minimização da Entropia Relativa e o Dólar Fu- turo}

Nesta seção iremos analisar a minimização da entropia relativa entre duas distribuições discretas de probabilidade $P$ e $Q$ sujeitas à restrições impostos pelo preço negociado em mercado do dólar futuro.

A função objetiva, a entropia relativa, é dada por:

$$
D(Q, P)=\sum_{i=1}^{n} q_{i} \log \frac{q_{i}}{p_{i}}
$$

com $P=\left\{p_{1}, \ldots, p_{n}\right\}$ um conjunto de probabilidades obtidas a priori através de dados históricos e $Q=\left\{q_{1}, \ldots, q_{2}\right\}$ variáveis à determinar. A equação esta sujeita as seguintes restrições:

$$
\left\{\begin{array}{l}
\phi_{1}=\sum_{i=1}^{n} q_{i}-1 \\
\phi_{2}=\sum_{i=1}^{n} S_{i} q_{i}-F
\end{array}\right.
$$


Aplicando o método dos Multiplicadores de Lagrange para obter o mínimo da função $D(Q, P)$ temos:

$$
d D(Q, P)=\left\{\sum_{i=1}^{n} \log \frac{q_{i}}{p_{i}}+1\right\}+\lambda_{1} d \phi_{1}+\lambda_{2} d \phi_{2}=0
$$

Observe que recaímos no mesmo problema resolvido no primeiro capítulo e cuja solução é dada pela equação (2.34). Portanto a solução é obtida resolvendo para $\lambda_{2}$ a equação abaixo:

$$
\sum_{i=1}^{n} S_{i} \frac{e^{-\lambda_{2} S_{i}}}{\sum_{i=1}^{n} p_{i} e^{-\lambda_{2} S_{i}}} p_{i}-F=0
$$

\subsection{O modelo}

O modelo amplamente difundido e utilizado pelo mercado financeiro para o apreçamento de opções de câmbio é o modelo de Garman-Kohlhagen.

Uma das características deste modelo é considerar a volatilidade do ativo objeto é considerada constante entre a data de inicio da operação até o seu vencimento.

Empiricamente observa-se que esta consideração não é verdadeira e verifica-se que a volatilidade é uma função do tempo e do valor de exercício da opção.

Neste modelo iremos considerar a componente da volatilidade que é dependente do tempo, também conhecida como estrutura a termo da volatilidade, ficando para um estudo posterior a análise da dependência em relação ao valor de exercício da opção, também conhecida como Assimetria.

O modelo que será utilizado para simular o processo difusivo do câmbio brasileiro será o modelo de árvores trinomiais.

O modelo proposto irá utilizar árvores cujas probabilidades de transição para cada nó serão obtidas minimizando a entropia relativa entre as probabilidades históricas e a informação contida no mercado de câmbio que estão sendo refletidas na cotação dos preços do dólar spot, dólar futuro e taxas pré e cupom. 
O modelo consiste em construir uma árvore trinomial recombinante utilizando a equação (4.21) iniciando na data analisada e terminando na data de vencimento do contrato de dólar futuro seguinte negociado na BM\&F. O valor da volatilidade $\sigma$ é obtido através do método $E W M A$ com período de 63 dias e fator de decaimento $(\lambda)$ igual 0,94 , como sugerido pelo RiskMetrics ${ }^{1}$.

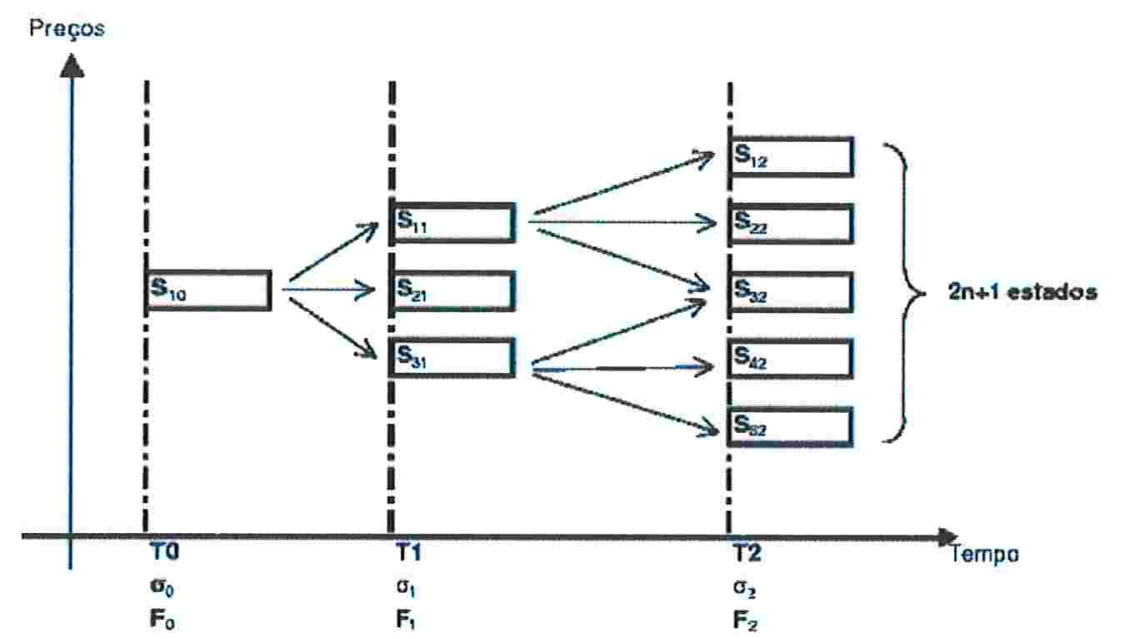

Figura 4.6: Construção da árvore trinomial. Note que o número de nós para cada intervalo de tempo é uma função de $2 n+1$, onde $n$ é o número de intervalos de tempo entre o instante inicial e t.

Note que o número de nós que a árvore pode ter para cada intervalo de tempo $\Delta t$ esta relacionado com o número de intervalos de tempo contidos entre o instante inicial até o intervalo de tempo considerado. Para $n$ intervalos de tempo contidos entre o instante inicial até o instante considerado teremos $2 n+1$ nós na Árvore.

De posse de todos os preços de todos os nós da árvore, calculamos todas as probabilidades de transição histórica (probabilidades $P$ ). Para isso utilizou-se valores históricos da cotação de fechamento do dólar de 63 dias anteriores à data analisada.

Tomando o conjunto das probabilidades a priori $P$ mais o dólar futuro calculado (equação (3.1)) para cada instante de tempo $\Delta t$ da árvore, pode-se, utilizando a expressão

\footnotetext{
${ }^{1}$ Conjunto de documentações técnicas oferecidas e mantidas gratuitamente pelo banco JP Morgan com a finalidade de promover a cultura e gerenciamento de risco
} 
(4.25) minimizar a entropia relativa, obtendo assim as novas probabilidades calibradas entropicamente para cada nó da árvore.

Sabendo que para cada instante de tempo $\Delta t$ da árvore vale a expressão:

$$
\sum_{i=1}^{n} q_{i}\left(S_{i}-F\right)^{2}=F \sigma^{2}+O(\Delta t) \Rightarrow \sigma^{2} \approx \frac{\sum_{i=1}^{n} q_{i}\left(S_{i}-F\right)^{2}}{F}
$$

onde $F$ é o dólar Futuro e $S_{i}$ são os valores dos preços de cada nó já calculados da árvore, pode-se através da equação (4.26) obter a volatilidade local para cada intervalo de tempo $\Delta t$.

De posse de todas as volatilidades para cada instante de tempo obtidas pela equação (4.26), pode-se construir a estrutura a termo da volatilidade e realizar uma simulação de Monte Carlo, onde para cada intervalo de tempo utiliza-se a volatilidade correspondente que foi calculada da forma descrita acima.

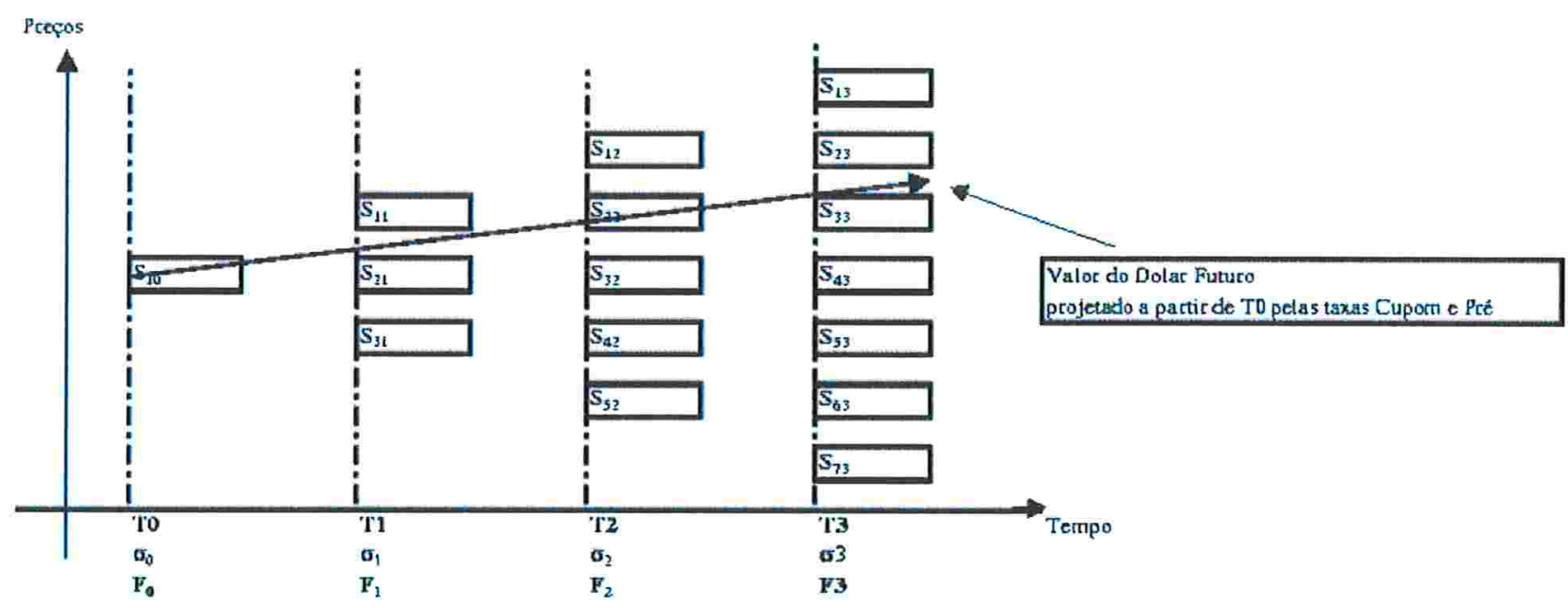

Figura 4.7: Esquema que representa uma árvore trinomial e a evolução temporal do dólar Futuro. O valor dólar Futuro dos intervalos de tempo intermediários entre o instante inicial e o vencimento do primeiro contrato Futuro são calculados a partir do dólar spot e das curvas Pré e Cupom. 
Quando estamos minimizando a entropia relativa entre as probabilidades históricas, e as ajustadas ao risco, utilizando a informação contida no dólar futuro, estamos nada mais nada menos do que redistribuindo as probabilidades de tal forma que "retiramos" probabilidades dos nós da árvore trinomial que apresentam preços mais distantes do dólar Futuro e "concentramos" mais probabilidades nos nós da árvore que possuem preços próximos ao do dólar futuro.

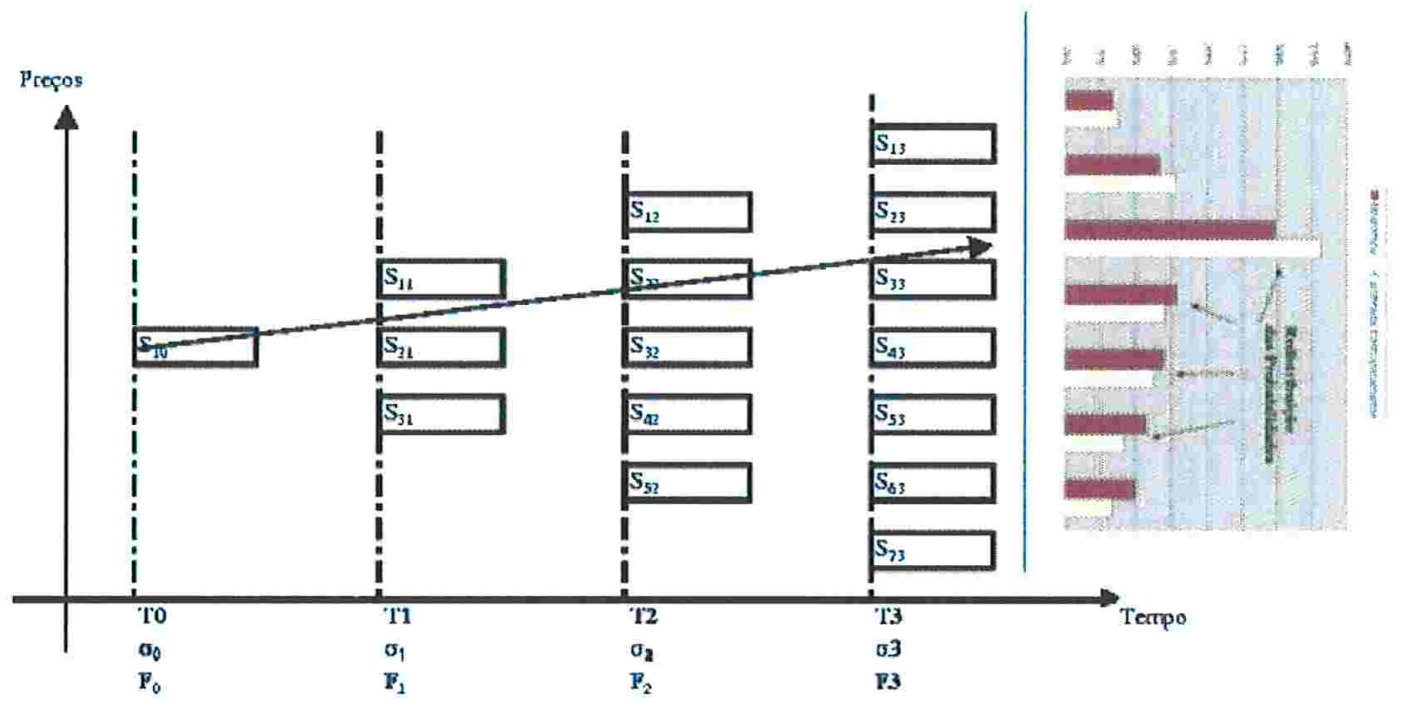

Figura 4.8: Esquema mostrando que a calibração entrópica "retira" valores das probabilidades dos nós da árvore que estão mais afastados do valor do dólar Futuro projetado e concentra-os nos nós com valores próximos ao do dólar futuro. 


\section{Capítulo 5}

\section{Estratégias de Avaliações de Opções de Câmbio}

Nesta sessão será calibrado e implementado o modelo sugerido no capítulo anterior. Para o cálculo das probabilidades a priori serão utilizados dados históricos do mercado de câmbio brasileiro.

\subsection{Comportamento Histórico do Câmbio brasileiro}

Este trabalho toma como base para análise os dados históricos compreendidos entre Janeiro de 2002 até Março de 2003. Este período é marcado pelas eleições presidenciais que ocorreram no país no mês de Outubro de 2002 e que influenciaram visivelmente no câmbio brasileiro.

Observando as figuras (5.1) e (5.2) verifica-se que a corrida para a sucessão presidencial influenciou na evolução da cotação do dólar e conseqüentemente em sua volatilidade.

O impacto também pode ser observado na estrutura a termo das taxas de juros Pré e Cupom provocando uma alteração em seus comportamentos, podendo ser observado nas Figura(5.3) e (5.4).

Este comportamento atípico apresentado na cotação do dólar e nas estruturas a termo 
Evoluçâo da Cotaçāo Spot RealidDolar

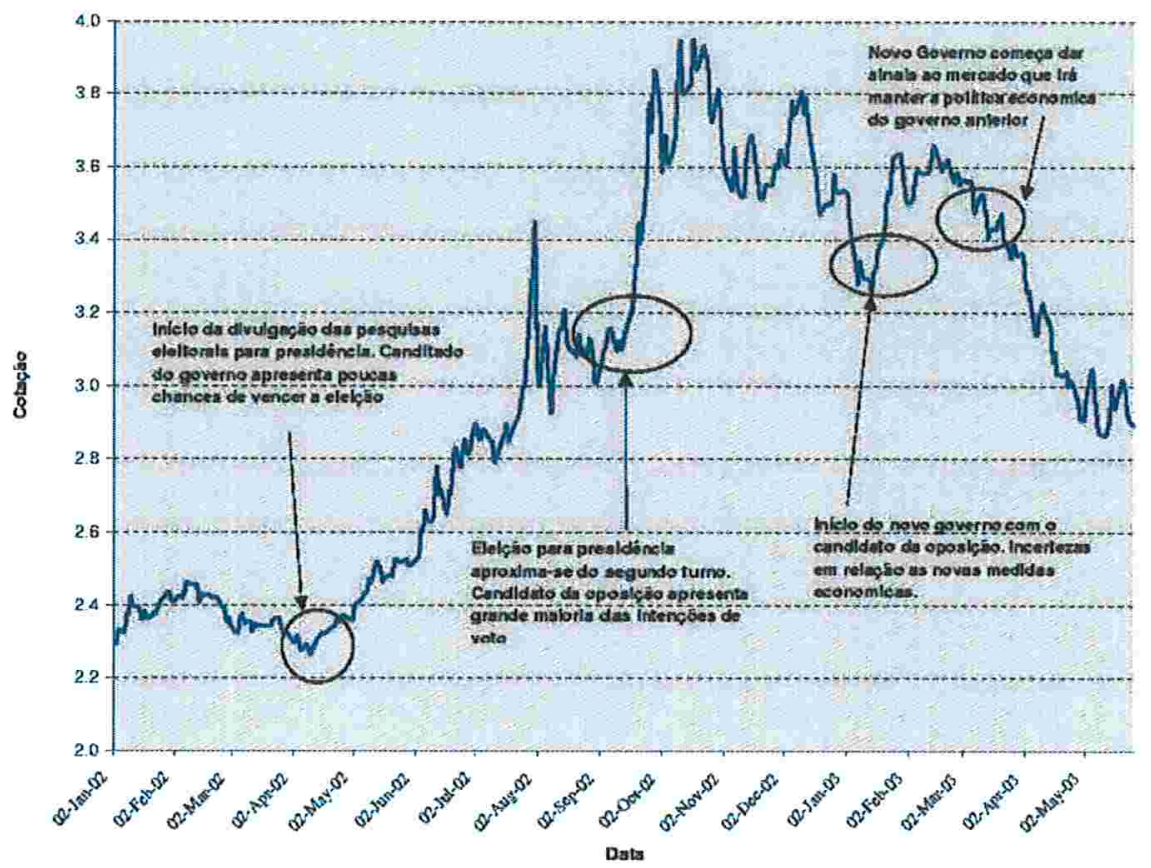

Figura 5.1: Comportamento da cotação do dólar spot entre Janeiro de 2002 a Março de 2003 onde pode-se observar o efeito provocado pelas eleições presidenciais na cotação do dólar

das taxas de juros pode ser atribuído a aversão dos agentes do mercado financeiro, até então, a uma possível vitória do candidato da oposição ao governo vigente.

Justamente nestes períodos atípicos torna-se uma tarefa difícil apreçar opções, de forma que considerar a volatilidade como uma variável constante, como presume o modelo de Garman-Kohlhagen, pode não ser uma boa premissa.

A seguir temos a estrutura a termo das taxas Pré e cupom deste período. Note como ocorre uma grande mudança de comportamento destas taxas. Na Figura(5.3) nota-se que a estrutura a termo da curva cupom possui uma taxa média superior ao da curva pré enquanto na Figura(5.4) ocorre exatamente o contrário.

Em períodos de normalidade (períodos calmos) a taxa média da curva pré é superior ao da curva cupom mas em períodos de turbulência (grande incerteza) ocorre o contrário.

$\mathrm{O}$ aumento da taxa cupom em níveis superiores ao da taxa pré justifica-se pela alto 


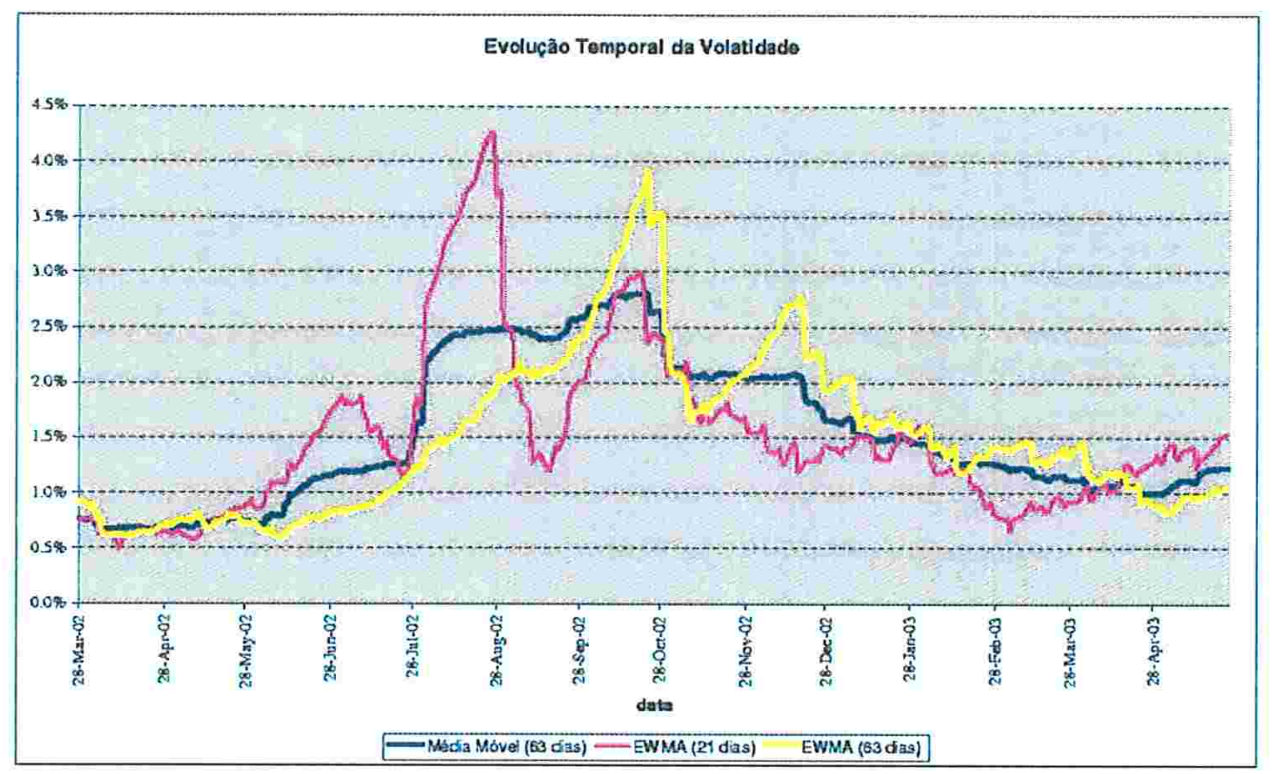

Figura 5.2: Evolução da volatilidade histórica entre Janeiro de 2002 a Março de 2003. Foram calculadas volatilidades utilizando média móvel de 63 dias e EWMA de 63 e 21 dias

risco atribuído pelos investidores a "saúde" financeira do país. Nestes períodos de turbulência instala-se me todo o mercado uma grande incerteza em relação a capacidade do governo honrar as sua dívidas e da capacidade de tomada de novas medidas econômicas com a finalidade de conter uma crise.

O resultado de tudo isso é que os agentes de mercado começam a exigir um prêmio de risco maior que o anterior para investir no país, sendo refletido na estrutura a termo das taxas de juros.

O efeito na taxa cupom deu-se em maior escala que a taxa pré devido na ocasião ter-se tido uma grande incerteza em relação as novas medidas de controle de capital estrangeiro que poderia ser adotado pelo governo de oposição, que até então liderava as pesquisas eleitorais. 
Estrutura a termo - 18 Setembro 2002

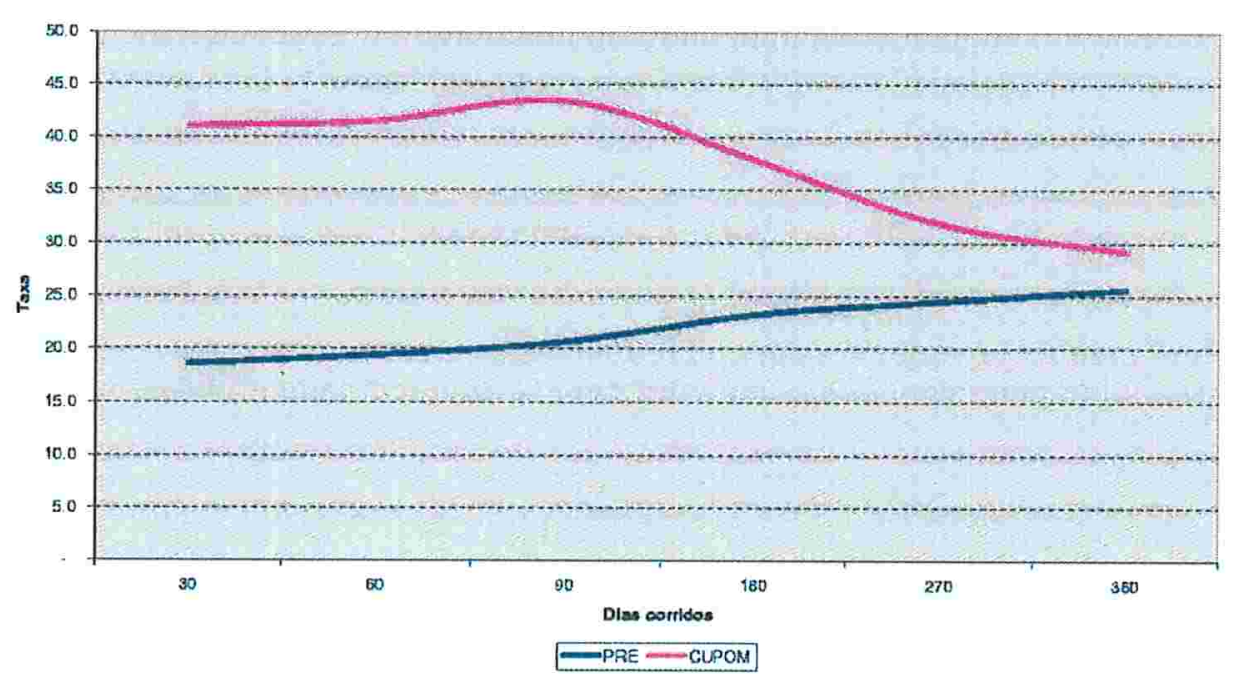

Figura 5.3: Estrutura a termo - 18 Setembro de 2002. Alguns dias antes das eleições do segundo turno onde todas as pesquisas eleitorais mostravam maioria na intenção de votos para o candidato da oposição.

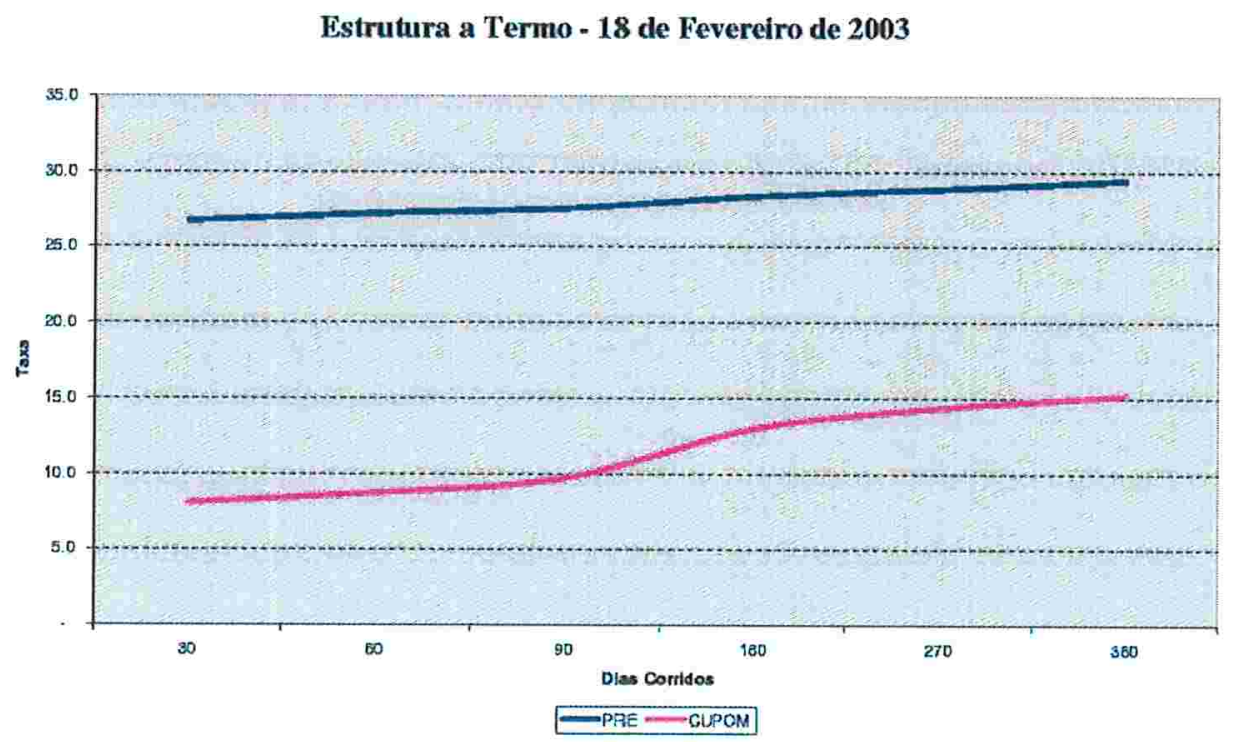

Figura 5.4: Estrutura a Termo - 18 Fevereiro 2003. Mercado mostra-se mais calmo e a estrutura a termo das taxas de juros apresentam um comportamento semelhante ao período anterior a crise, embora os níveis ainda apresentavam-se maiores 


\subsection{Resultados Obtidos}

Para efeito de análise e comparação entre o modelo proposto para apreçamento e o de Garman-Kohlhagen foram determinadas três datas que se apresentam abaixo:

- 18 de Setembro de 2002: Período pré segundo turno das eleições e quando todas as pesquisas de intenção de voto apontam o candidato da oposição como vencedor.

- 13 de Janeiro de 2003: Início do governo de oposição. Agentes do mercado possuíam dúvidas em relação as novas medidas econômicas que o novo governo poderia vir a tomar.

- 18 de Fevereiro de 2003: Período pós eleição com o candidato da oposição sendo o vencedor e após sinalização ao mercado que a política monetária e econômica não seriam alteradas.

A seguir serão apresentados as árvores obtidas, as probabilidades de transição (histórica e calibrada entropicamente) e simulação de Monte Carlo obtidas para os dias citados acima.

\section{Resultados para 18 de Setembro}

Árvore Trinomial - 18 Setembro 2002

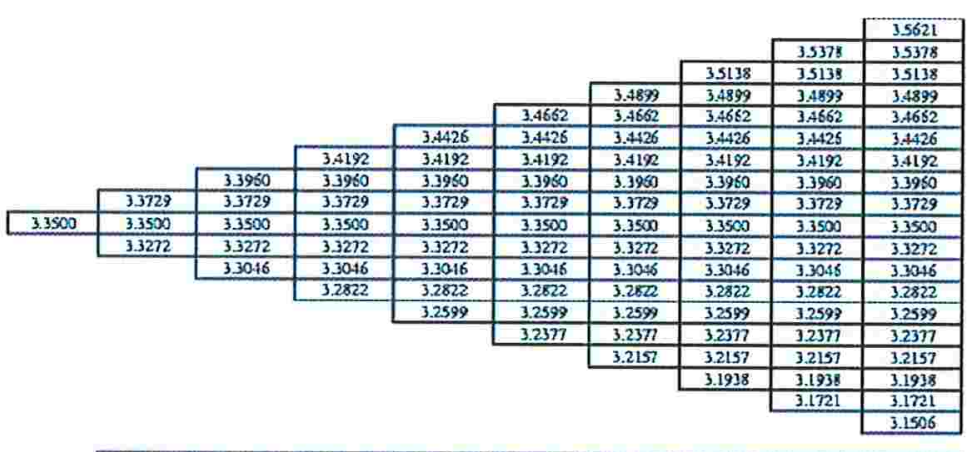

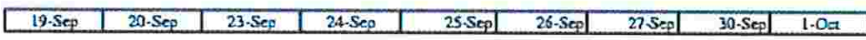

Figura 5.5: Árvore trinomial para 18 de Setembro de 2002. 


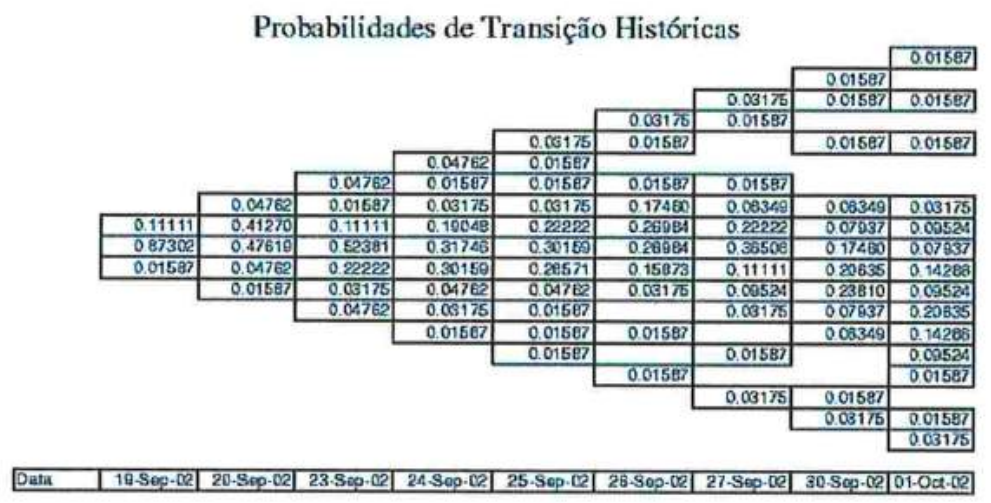

Figura 5.6: Distribuição de probabilidades de transição históricas para 18 de Setembro de 2002 .

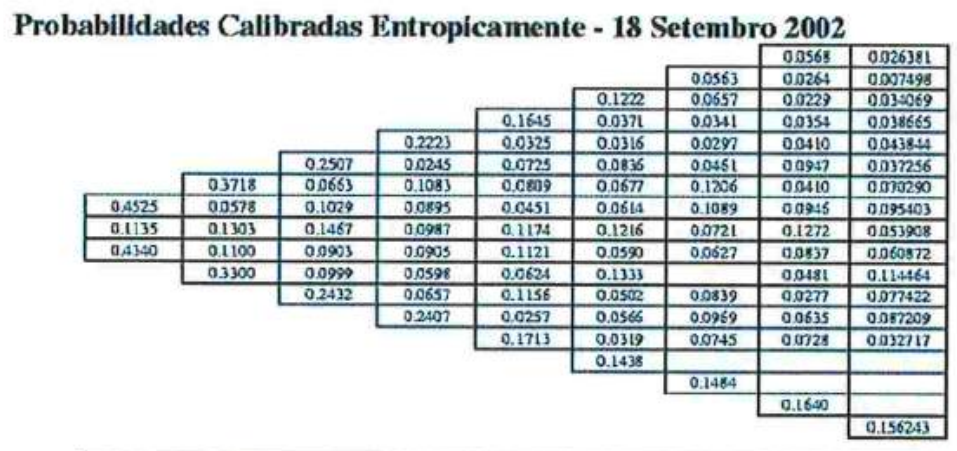

Figura 5.7: Distribuição de probabilidades calibradas entropicamente utilizando o dólar futuro para 18 de Setembro de 2002. 


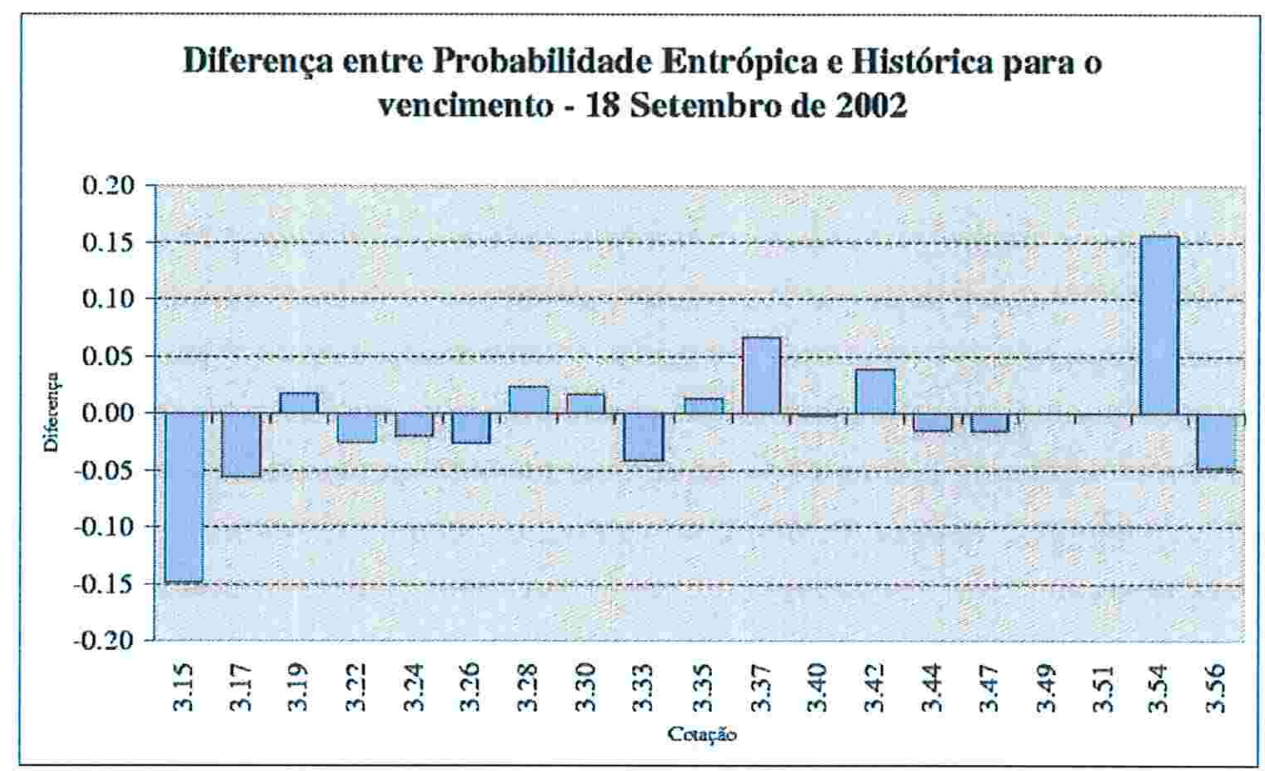

Figura 5.8: Gráfico que apresenta a redistribuição de probabilidades entre a histórica e a calibrada entropicamente. 


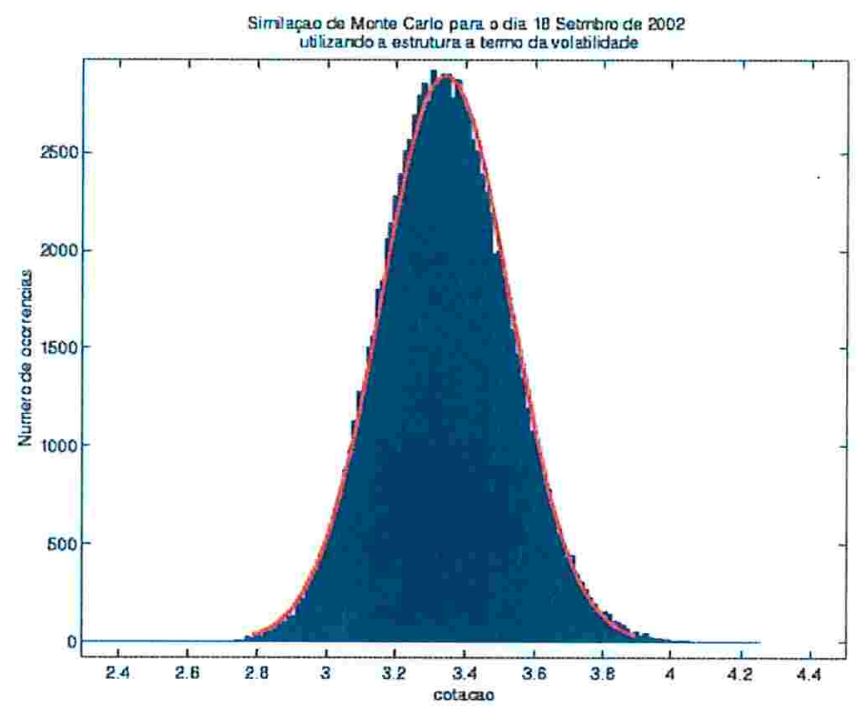

Figura 5.9: Simulação de Monte Carlo utilizando as volatilidades obtidas através da calibração entrópica. Foram gerados 100.000 eventos.

\begin{tabular}{|l||l|}
\hline Medidas Estatísticas & Valor \\
\hline \hline Média $(\mathrm{R} \$)$ & 3,3422 \\
\hline Desvio Padrão & 0,1847 \\
\hline Assimetria & 0,0886 \\
\hline Curtose & 4,0915 \\
\hline
\end{tabular}

Tabela 5.1: Tabela contendo os dados estatísticos da distribuição obtida pela simulação de Monte Carlo para o dia 18 de Setembro de 2002. 


\begin{tabular}{|c||c|c|c|c|}
\hline Data & Volatilidade Anualizada & Valor do Dólar Futuro (R\$) & Taxa Pré (\%) & Taxa Cupom (\%) \\
\hline 19-Set-02 & $18,65 \%$ & 3,3505 & 16,46 & 11,38 \\
\hline 20 -Set-02 & $24,17 \%$ & 3,3509 & 16,54 & 11,38 \\
\hline $23-$ Set-02 & $26,35 \%$ & 3,3497 & 16,57 & 17,77 \\
\hline $24-$ Set-02 & $29,82 \%$ & 3,3484 & 16,59 & 20,96 \\
\hline 25 -Set-02 & $30,36 \%$ & 3,3471 & 16,60 & 22,88 \\
\hline 26 -Set-02 & $31,12 \%$ & 3,3458 & 16,60 & 24,16 \\
\hline 27-Set-02 & $32,32 \%$ & 3,3390 & 16,61 & 33.80 \\
\hline $30-$ Set-02 & $32,69 \%$ & 3,3377 & 16,61 & 33,39 \\
\hline 01-Out-02 & $33,93 \%$ & 3,3365 & 16,61 & 32,99 \\
\hline
\end{tabular}

Tabela 5.2: Tabela contendo, volatilidades, projeções do dólar Futuro e taxas utilizadas para a obtenção da projeção do dólar Futuro para o período de 18 de Setembro de 2002. O quotação do dólar spot para este período era de a R\$/USD 3,3500.

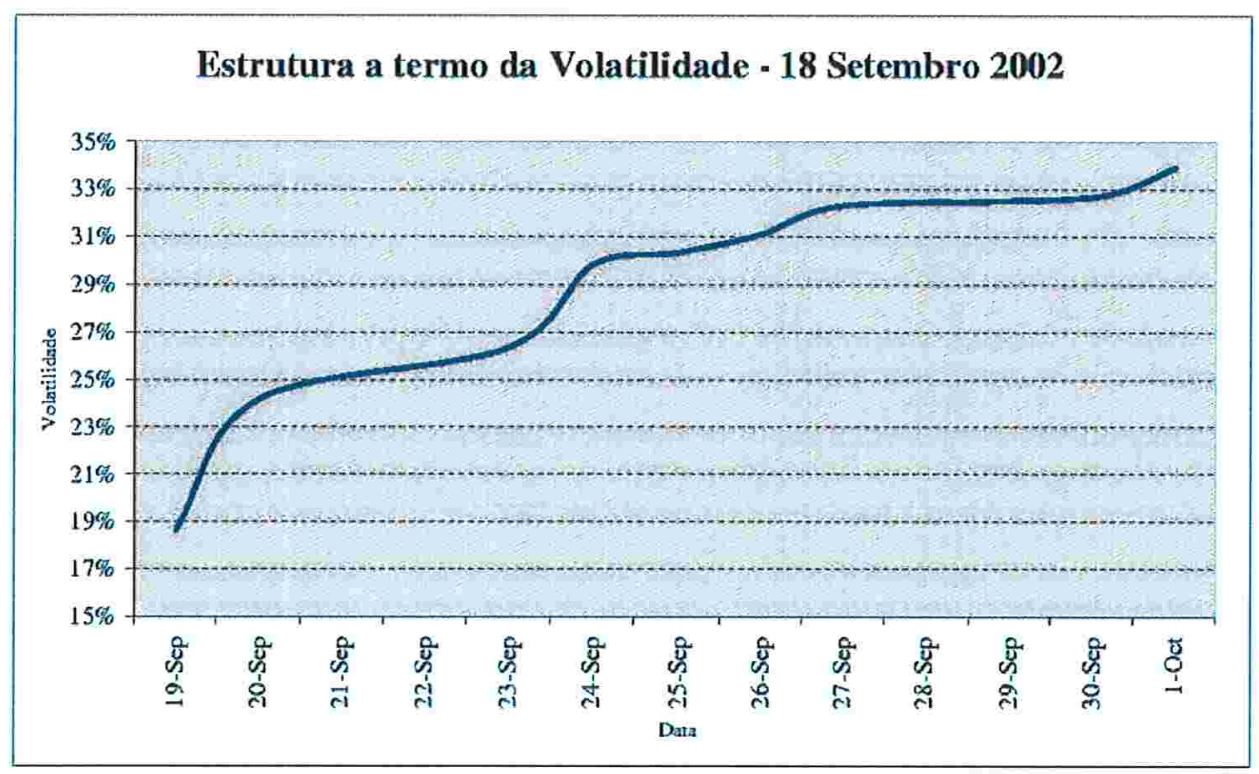

Figura 5.10: Estrutura a termo da volatilidade para o dia 18 de Setembro 2002 


\section{Resultados para 13 de Janeiro 2003}

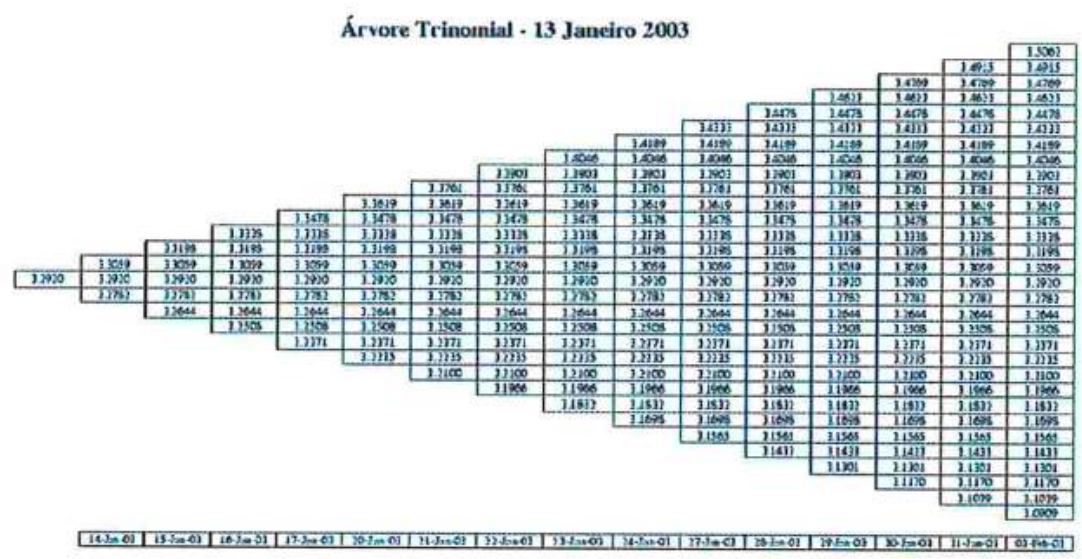

Figura 5.11: Árvore trinomial para 13 de Janeiro de 2003.

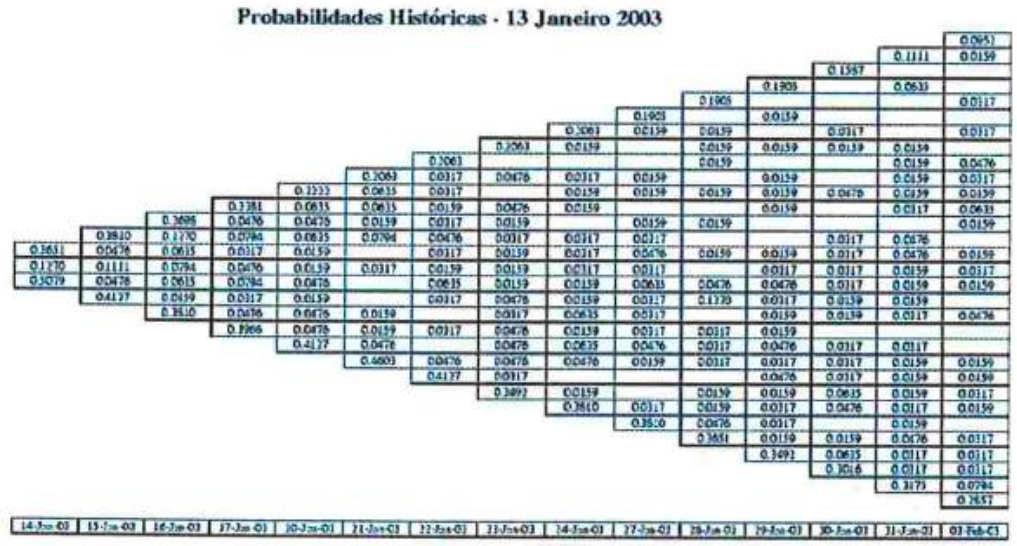

Figura 5.12: Distribuição de probabilidades de transição históricas para 13 de Janeiro de 2003. 


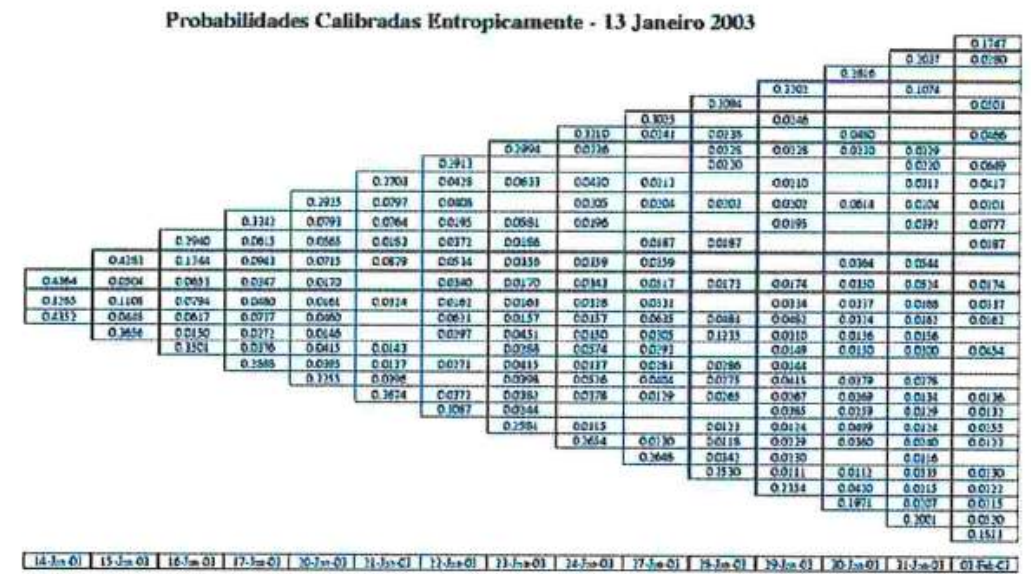

Figura 5.13: Distribuição de probabilidades calibradas entropicamente utilizando o dólar futuro para 13 de Janeiro de 2003.

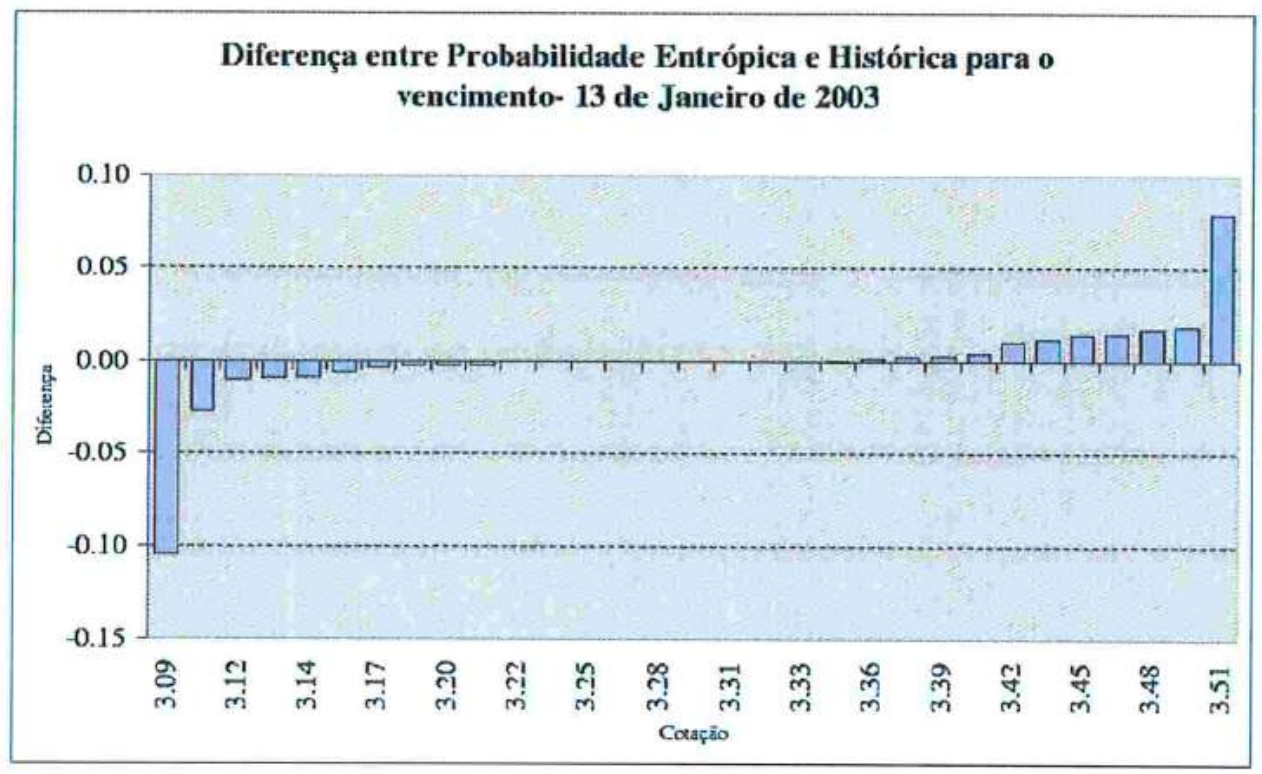

Figura 5.14: Gráfico que apresenta a redistribuição de probabilidades entre a histórica e a calibrada entropicamente. 


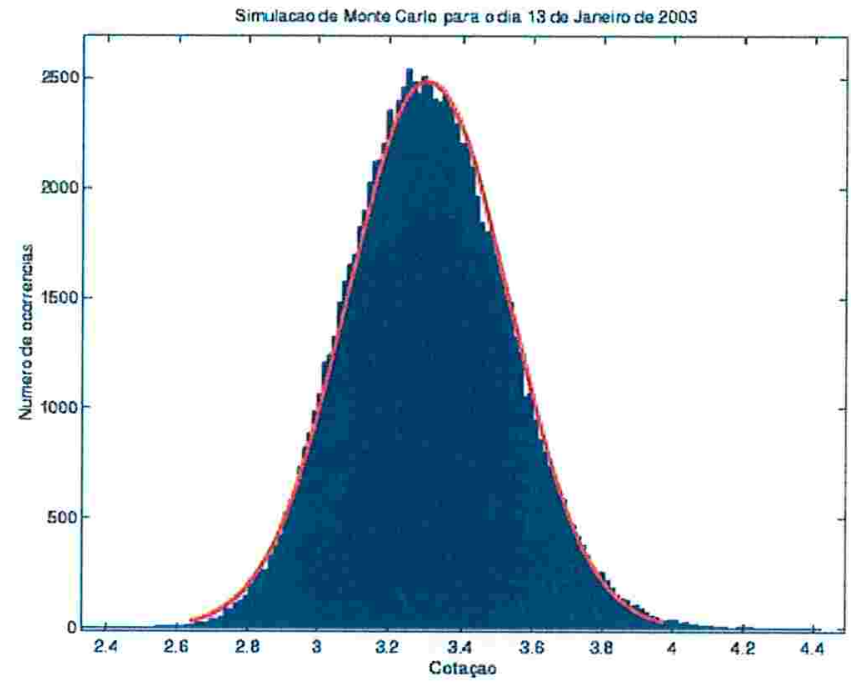

Figura 5.15: Simulação de Monte Carlo utilizando as volatilidades obtidas através da calibração entrópica. Foram gerados 100.000 eventos.

\begin{tabular}{|l||c|}
\hline Medidas Estatísticas & Valor \\
\hline \hline Média (R\$) & 3,3031 \\
\hline Desvio Padrão & 0,2237 \\
\hline Assimetria & 0,1605 \\
\hline Curtose & 3,5199 \\
\hline
\end{tabular}

Tabela 5.3: Tabela contendo os dados estatísticos da distribuição obtida pela simulação de Monte Carlo para o dia 13 de Janeiro de 2003. 


\begin{tabular}{|c||c|c|c|c|}
\hline Data & Volatilidade Anualizada & Valor do Dólar Futuro (R\$) & Taxa Pré (\%) & Taxa Cupom (\%) \\
\hline 14-Jan-03 & $11,33 \%$ & 3,2930 & 22,17 & 13,55 \\
\hline 15-Jan-03 & $15,44 \%$ & 3,2940 & 22,23 & 13,55 \\
\hline 16-Jan-03 & $17,83 \%$ & 3,2932 & 22,26 & 13,15 \\
\hline 17-Jan-03 & $20,36 \%$ & 3,2972 & 22,27 & 16,65 \\
\hline 20-Jan-03 & $23,35 \%$ & 3,2943 & 22,27 & 15,80 \\
\hline 21-Jan-03 & $26,13 \%$ & 3,2936 & 22,28 & 16,88 \\
\hline 22-Jan-03 & $26,95 \%$ & 3,2960 & 22,28 & 16,24 \\
\hline 23-Jan-03 & $28,35 \%$ & 3,2951 & 22,28 & 15,75 \\
\hline 24-Jan-03 & $30,10 \%$ & 3,2989 & 22,28 & 18,12 \\
\hline 27-Jan-03 & $30,76 \%$ & 3,2965 & 22,29 & 17,55 \\
\hline 28-Jan-03 & $32,88 \%$ & 3,2956 & 22,29 & 17,08 \\
\hline 29-Jan-03 & $34,32 \%$ & 3,2983 & 22,29 & 16,68 \\
\hline 30-Jan-03 & $34,39 \%$ & 3,2975 & 22,29 & 16,35 \\
\hline 31-Jan-03 & $34,79 \%$ & 3,3016 & 22,29 & 17,83 \\
\hline 03-Fev-03 & $34,98 \%$ & 3,2996 & 22,29 & 17,46 \\
\hline
\end{tabular}

Tabela 5.4: Tabela contendo, volatilidades, projeções do dólar Futuro e taxas utilizadas para a obtenção da projeção do dólar Futuro para o período de 13 de Janeiro de 2003 . O quotação do dólar spot para este período era de a R\$/USD 3,2930.

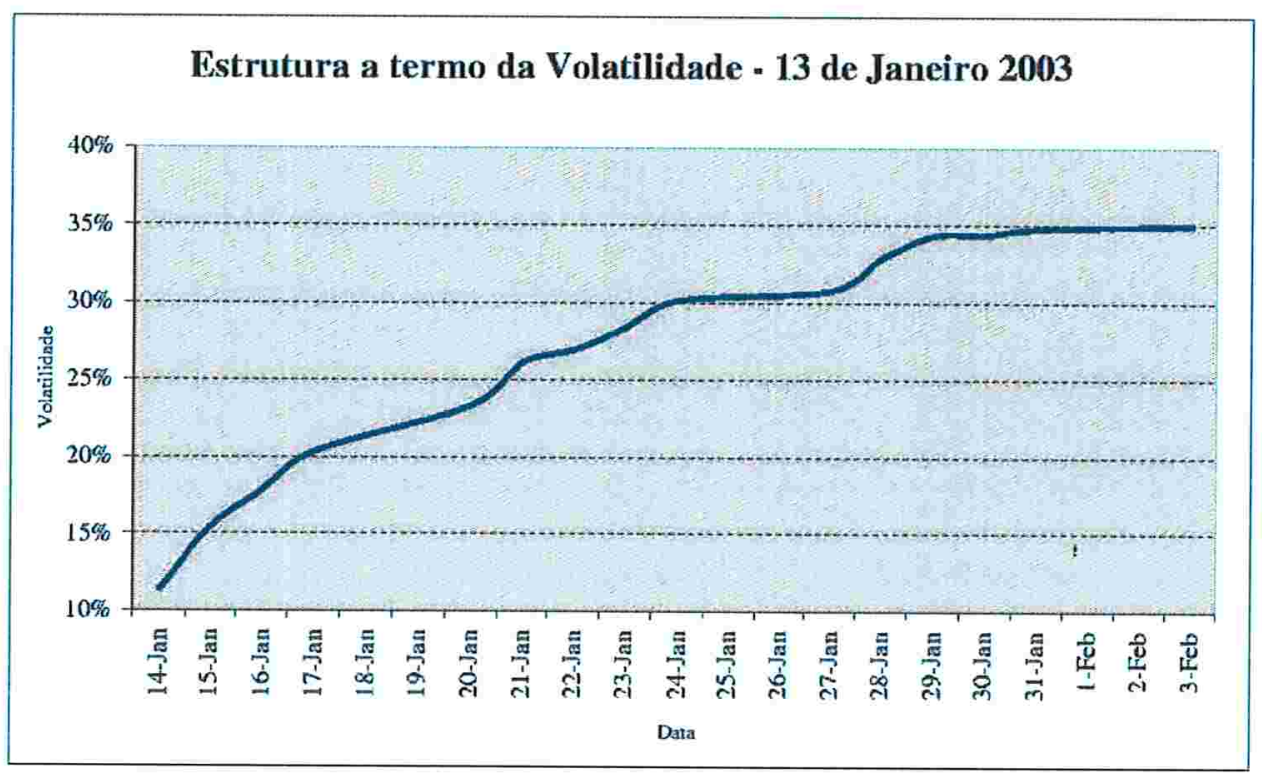

Figura 5.16: Estrutura a termo da volatilidade para o dia 13 de Janeiro 2003 


\section{Resultados para 18 de Fevereiro 2003}

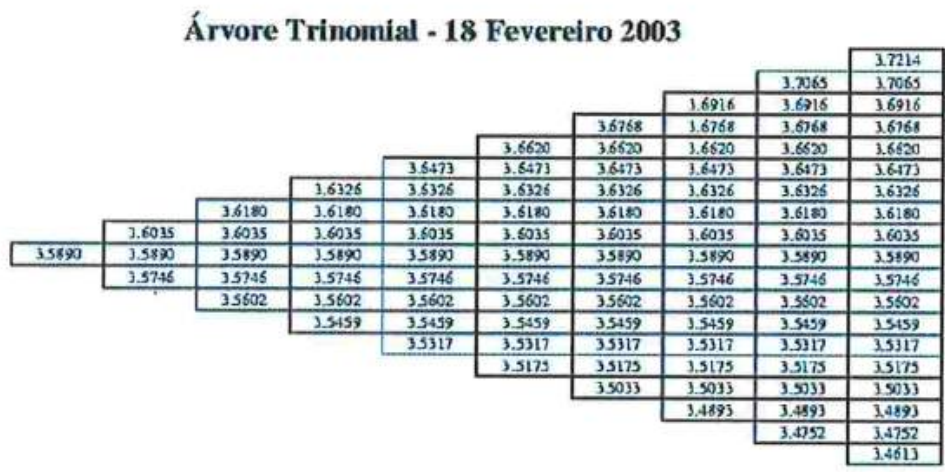

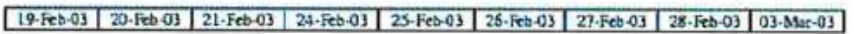

Figura 5.17: Árvore trinomial para 18 de Fevereiro de 2003.

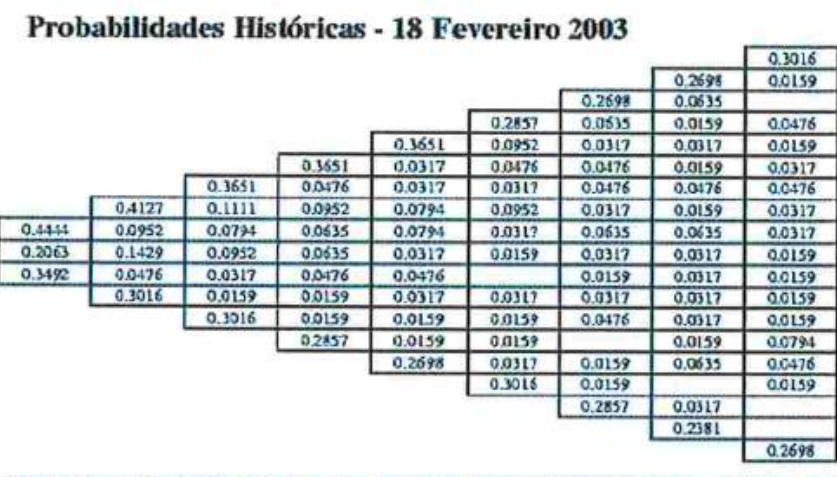

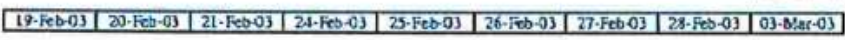

Figura 5.18: Distribuição de probabilidades de transição históricas para 18 de Fevereiro de 2003. 


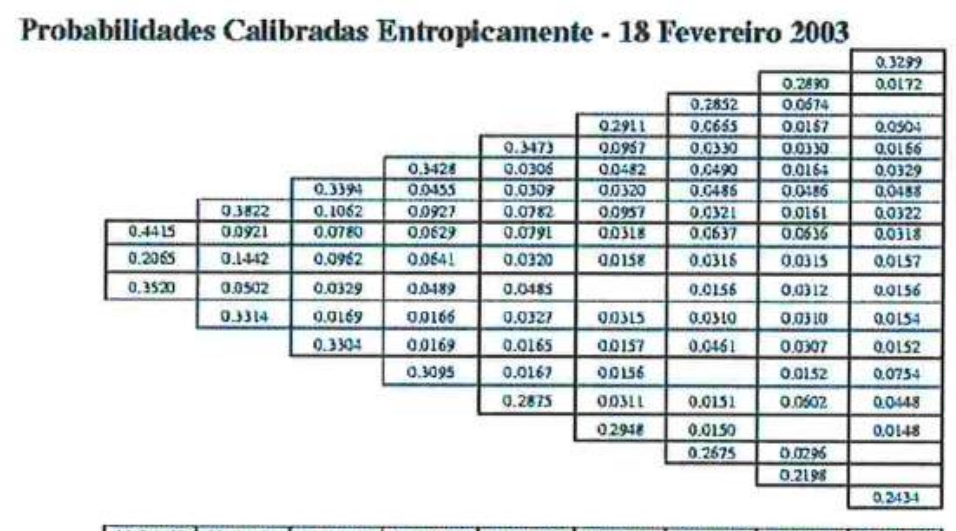

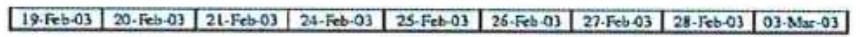

Figura 5.19: Distribuição de probabilidades calibradas entropicamente utilizando o dólar futuro para 18 de Fevereiro de 2003.

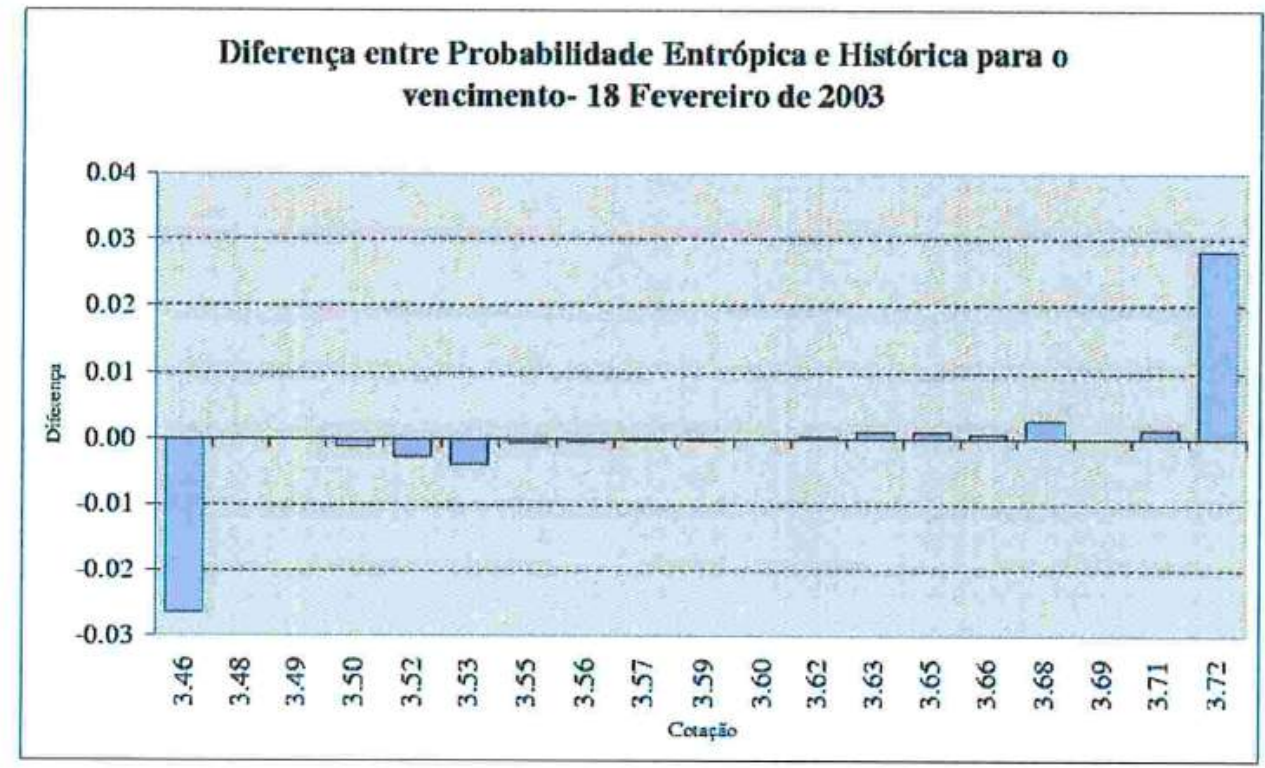

Figura 5.20: Gráfico que apresenta a redistribuição de probabilidades entre a histórica e a calibrada entropicamente. 


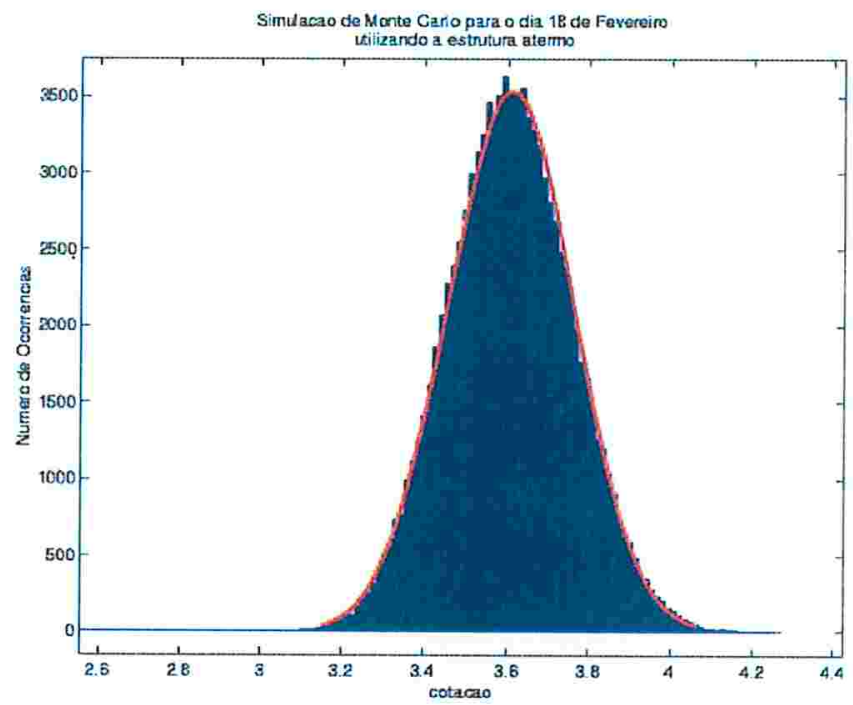

Figura 5.21: Simulação de Monte Carlo utilizando as volatilidades obtidas através da calibração entrópica. Foram gerados 100.000 eventos.

\begin{tabular}{|l||c|}
\hline Medidas Estatísticas & Valor \\
\hline \hline Média (R\$) & 3,60 \\
\hline Desvio Padrão & 0,1525 \\
\hline Assimetria & $-0,0251$ \\
\hline Curtose & 6,1197 \\
\hline
\end{tabular}

Tabela 5.5: Tabela contendo os dados estatísticos da distribuição obtida pela simulação de Monte Carlo para o dia 18 de Fevereiro de 2003. 


\begin{tabular}{|c||c|c|c|c|}
\hline Data & Volatilidade Anualizada & Valor do Dólar Futuro (R\$) & Taxa Pré (\%) & Taxa Cupom(\%) \\
\hline 19-Fev-03 & $10,73 \%$ & 3,5862 & 22,54 & 13,84 \\
\hline 20-Fev-03 & $14,77 \%$ & 3,5912 & 23,07 & 13,84 \\
\hline $21-F e v-03$ & $17,90 \%$ & 3,5928 & 23,24 & 9,82 \\
\hline $24-F e v-03$ & $20,42 \%$ & 3,5949 & 23,33 & 7,82 \\
\hline 25-Fev-03 & $22,54 \%$ & 3,5970 & 23,39 & 6,61 \\
\hline 26-Fev-03 & $25,09 \%$ & 3,5991 & 23,42 & 5,81 \\
\hline 27-Fev-03 & $26,08 \%$ & 3,6012 & 23,45 & 6,26 \\
\hline 28-Fev-03 & $27,40 \%$ & 3,6024 & 23,47 & 5,63 \\
\hline 03-Fev-03 & $29,36 \%$ & 3,6046 & 23,54 & 5,67 \\
\hline
\end{tabular}

Tabela 5.6: Tabela contendo, volatilidades, projeções do dólar Futuro e taxas utilizadas para a obtenção da projeção do dólar Futuro para o período de 13 de Janeiro de 2003. O quotação do dólar spot para este período era de a R\$/USD 3,5890.

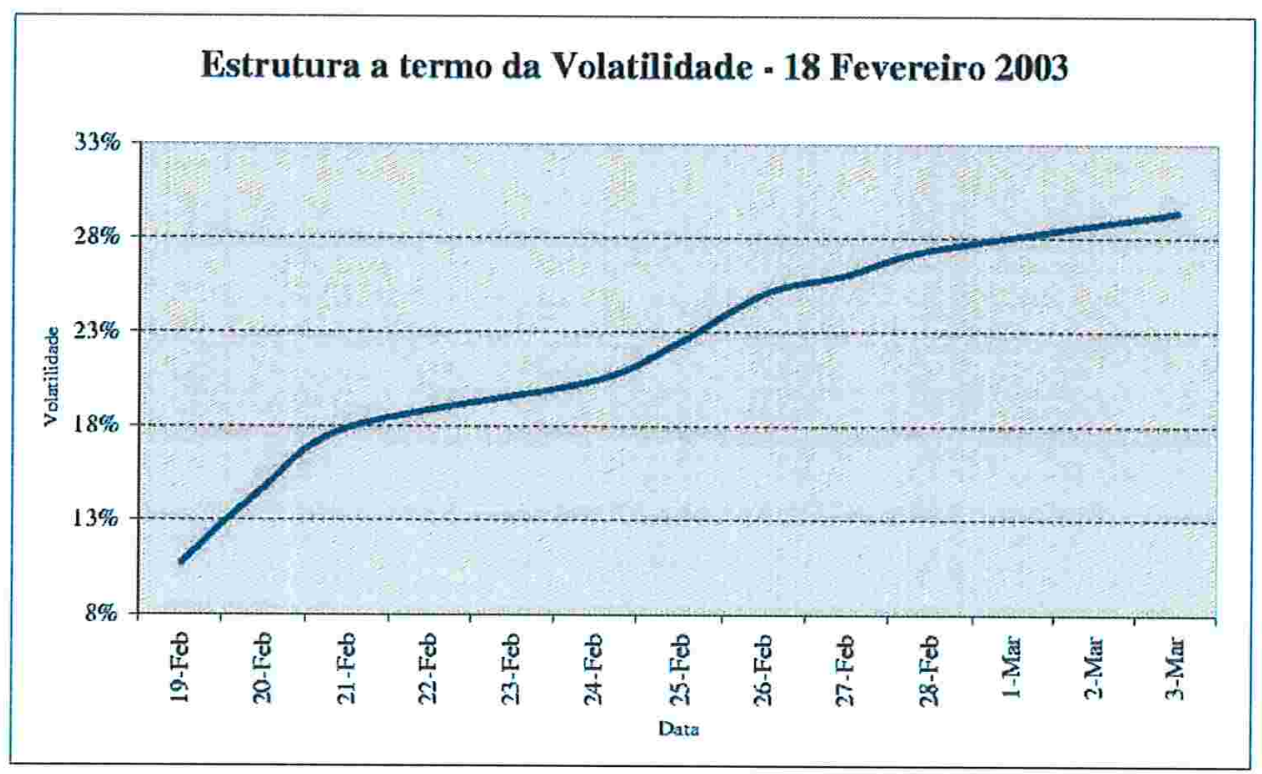

Figura 5.22: Estrutura a termo da volatilidade para o dia 18 de Fevereiro 2003 


\subsection{Resumo dos resultados obtidos}

A tabela abaixo apresenta um resumo dos valores obtidos pelo modelo de GarmanKohlhagen e pelo modelo trinomial calibrado utilizando a minimização da entropia relativa. Nesta tabela é feita uma comparação entre as volatilidades negociadas pelo agentes de mercado e as obtidas pelo modelo proposto para a data de vencimento do primeiro contrato de dólar futuro do período analisado.

\begin{tabular}{|l|c|c|c|}
\hline & $18-$ Set-02 & $13-\mathrm{Jan}$-03 & 18 -Fev-03 \\
\hline Volatilidade de Mercado anualizada & $35,38 \%$ & $23,74 \%$ & $23,73 \%$ \\
\hline Média das volatilidades anualizadas da Estrutura a termo & $28,82 \%$ & $26,80 \%$ & $21,59 \%$ \\
\hline Volatilidade anualizada da estrutura a termo no vencimento & $33,93 \%$ & $34,98 \%$ & $29,36 \%$ \\
\hline Volatilidade histórica anualizada - EWMA 63 dias com $\lambda=0,93$ & $33,50 \%$ & $26,67 \%$ & $19,53 \%$ \\
\hline Preço de mercado para op̧̧ão com $\triangle=0,5(\mathrm{R} \$)^{1}$ & 0,0847 & 0,0732 & 0,0623 \\
\hline $\begin{array}{l}\text { Preço para opção com } \Delta=0,5 \text { utilizando a estrutura a termo de volatilidade } \\
\text { obtida entropicamente e calculada via modelo de Monte Carlo (R\$) }\end{array}$ & 0,0740 & 0,0754 & 0,0553 \\
\hline
\end{tabular}

Tabela 5.7: Resumo e comparação dos resultados obtidos pelo modelo proposto e os valores negociados no mercado.

Pela tabela acima nota-se que os valores obtidos pelo modelo proposto estão de acordo com os valores negociados pelo mercado.

Pelos resultados obtidos notou-se que a redistribuição das probabilidades históricas deu-se de forma assimétrica. Percebeu-se também que a magnitude da redistribuição das probabilidades na árvore trinomial utilizando a idéia de minimização da entropia relativa foi muito baixa. Atribui-se este fato a baixa quantidade de informação que podem serem capturadas pelas cotações do dólar spot, dólar futuro e taxas de juros, fazendo com que o módulo da diferença entre as probabilidades obtidas historicamente e utilizando o conceito de minimização a entropia relativa sejam baixas na árvore trinomial.

\footnotetext{
${ }^{1} \mathrm{O}$ Valor da volatilidade de mercado $\sigma$ foi obtido através da matriz de volatilidades divulgada pela agência de notícias Reuters, enquanto que o preço da opção foi obtido pelo modelo de Garman
} 
Outro fato que pode ser observado é que a média da estrutura a termo da volatilidade calculada pelo modelo proposto aproxima-se do valor da volatilidade negociada para as opções de câmbio com vencimento igual ao do dólar futuro. 


\section{Capítulo 6}

\section{Conclusão}

Esta dissertação fez uma análise do conceito de entropia aplicada ao mercado de câmbio brasileiro.

Foi proposto um modelo para avaliação de opções de câmbio através da simulação de Monte Carlo utilizando uma estrutura a termo para a volatilidade. Esta estrutura da volatilidade foi obtida através de árvores trinomiais com probabilidades de transição calibradas entropicamente levando em consideração a informação contida na cotação do dólar spot, dólar Futuro e taxas de juros pré e cupom.

O modelo foi testado para alguns dias onde foram calculados preços de opções de câmbio que se apresentavam de acordo com os valores negociados pelo mercado. Gostaria de ressaltar que e o modelo foi testado apenas para opções no dinheiro, onde o efeito de curvatura da superfície de volatilidade é minímo.

Observou-se também que as novas probabilidades obtidas pela minimização da entropia relativa que levou em consideração as cotações do dólar futuro negociado pela $\mathrm{BM} \& \mathrm{~F}$, diferenciavam-se muito pouco das probabilidades obtidas de maneira histórica. Isto deve-se a baixa quantidade de informação que pode ser capturada pelas cotações do dólar spot, dólar futuro e taxas de juros negociadas pelo mercado.

Outro fato observado nos exemplos para o qual o modelo foi aplicado é de que a redistribuição das probabilidades foi feita de forma assimétrica. 
Outro fato observado foi de que a média da estrutura a termo da volatilidade obtida pelo método proposto aproxima-se do valor da volatilidade das opções de câmbio negociadas para a mesma data de vencimento do dólar futuro negociado pela BM\%F.

Uma das preocupações desta dissertação foi de apresentar todos os passos necessários para a avaliação de opções de tal forma que sirva de referência para aqueles que buscam se aprofundar no tema. 


\section{Apêndice A}

\section{Método para interpolação de taxa de}

\section{juros}

Neste apêndice será demonstrado como realizar a interpolação da taxa de juros pré a partir dos contratos de futuros de depósitos Inter-bancários de 1 dia. Estes contratos futuros negociados na BM\&F são também conhecidos como contratos de $D I$. A forma de interpolação apresentada a seguir não é única mas é a mais utilizada pelo mercado.

Os contratos de DI são negociados pelo seu PU. Denomina-se de PU o valor de $R \$ 100.000,00$ trazido a valor presente pela taxa de juros pré efetiva entre o instante em que o contrato foi negociado e a data de seu vencimento.

Estes contratos possuem o seu vencimento no primeiro dia útil de cada mês podendo serem negociados até o último dia útil do mês anterior ao seu vencimento.

Para exemplificar melhor como se dá a interpolação da taxa de juros entre dois contratos de DI com vencimentos diferentes será utilizado o exemplo abaixo:

\begin{tabular}{|c|c|c|}
\hline Vencimento & PU & Dias úteis para o vencimento \\
\hline \hline janeiro & 99.000 & 8 \\
\hline fevereiro & 98.000 & 30 \\
\hline
\end{tabular}

A taxa pré efetiva dos contratos exemplificados acima podem ser obtidas através da 
expressão 3.3 , portanto:

$$
\begin{aligned}
& r_{j a n}=\left(\frac{100.000}{99.000}\right)^{\frac{252}{8}} \\
& r_{f e v}=\left(\frac{100.000}{98.000}\right)^{\frac{252}{30}}
\end{aligned}
$$

A taxa pré para qualquer instante compreendido entre os instantes de vencimentos dos contratos futuros acima pode, então, ser calculada facilmente. O esquema abaixo auxiliará na compreensão:

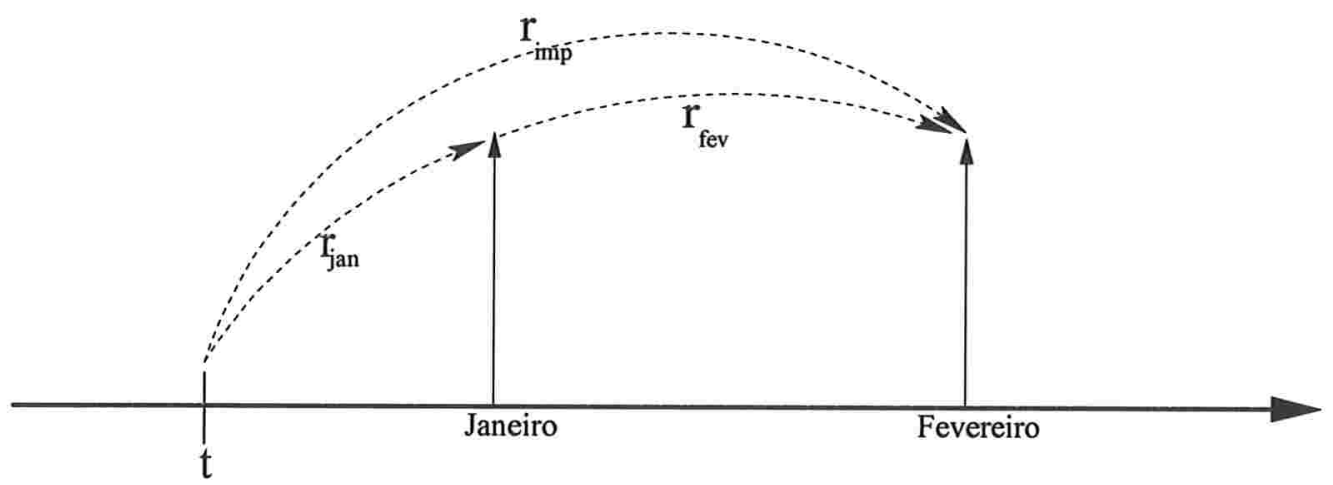

Figura A.1: Esquema que auxilia na compreensão da obtenção da estrutura a termo da taxa pré a partir dos contratos futuros de DI.

Os termos $r_{j a n}$ e $r_{f e v}$ são respectivamente as taxas pré efetivas obtidas a partir dos contratos futuros de DI com vencimentos em Janeiro e Fevereiro calculadas pelas expressões A.1 e A.2.

O termo $r_{i m p}$ é a taxa implícita entre os contratos. Para não ocorrer arbitragem a seguinte expressão deve ser respeitada.

$$
\left(1+r_{j a n}\right)^{\frac{8}{252}}\left(1+r_{i m p}\right)^{\frac{22}{252}}=\left(1+r_{f e v}\right)^{\frac{30}{252}}
$$

A partir da expressão acima podemos calcular o valor de $r_{i m p}$ uma vez que os valores de $r_{j a n}$ e $r_{f e v}$ já foram obtidos. Simplificando temos: 


$$
r_{i m p}=\left[\frac{\left(1+r_{f e v}\right)^{\frac{30}{22}}}{\left(1+r_{j a n}\right)^{\frac{8}{22}}}\right]^{\frac{252}{22}}-1
$$

Para o cálculo da taxa efetiva entre o instante atual e qualquer data de vencimento entre as datas dos contratos futuros de DI utiliza-se a seguinte expressão:

$$
r_{n}=\left[\left(1+r_{j a n}\right)^{\frac{8}{252}}\left(1+r_{i m p}\right)^{\frac{n-8}{252}}-1\right]^{\frac{252}{n}}
$$

onde $n$ é o número de dias úteis entre o instante atual e a data onde desejamos conhecer a taxa pré.

A estrutura a termo da taxa pré é obtida calculando-se a taxa pré para todos os dias úteis utilizando-se os contratos futuros de DI que são efetivamente negociados pela BM\&F e a expressão A.5. 


\title{
Apêndice B
}

\section{Programas Utilizados para análise}

Todos os programas utilizados para análise nesta dissertação foram desenvolvidos na linguagem MATLAB versão 6.0.0.88 release 12 de 22 de Setembro de 2000.

\section{B.1 Programa Principal}

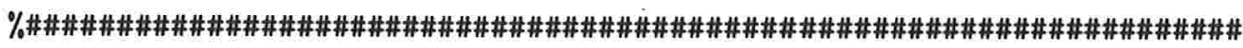

\%\# UNIVERSIDADE DE SAO PAULO

\#

\%\# MESTRADO PROFISSIONALIZANTE EM MODELAGEMA MATEMATICA EM FINANÇAS \#

\%\# PROGRAMA DE ANALISE

\#

\%\# AUTOR: PAULO ROBERTO LAGROTTA

\#

\%\#\#\#\#\#\#\#\#\#\#\#\#\#\#\#\#\#\#\#\#\#\#\#\#\#\#\#\#\#\#\#\#\#\#\#\#\#\#\#\#\#\#\#\#\#\#\#\#\#\#\#\#\#\#\#\#\#\#\#\#\#\#\#\#\#\#\#\#

\% ESTE PROGRAMA NECESSITA DE UM VETOR CONTENDO AS COTACOES DE \#

\% FECHAMENTO DO DOLAR SPOT CHAMADO vetor_fX E OUTRO VETOR CONTENDO \#

$\%$ AS TAXAS CHAMADO taxas.

\#

\% ABAIXO SEGEM OS PARAMETROS UTILIZADOS PARA ANALISE, BASTANDO \#

$\%$ APENAS DESCOMENTAR O DESEJADO \#
\end{abstract}

\%\# DEFINICAO DOS PARAMETROS A SEREM UTLIZADOS PAR DIFERENTES DIAS 
$\%$ \#\#\# 18 sep

$\%$ pto $=448$;

$\%$ dias_ate_venc $=9$;

$\%$ spot=vetor_fx (pto);

$\%$ janela $=63$;

$\%$ volat_hist $=\log (1+\operatorname{sqrt}($ dias_ate_venc $) * .0211) /$ dias_ate_venc ;

$\% \# \# 13$ jan

$\%$ pto $=530$;

$\%$ dias_ate_venc $=15$;

$\%$ spot=vetor_fx (pto);

$\%$ janela $=63$;

$\%$ volat_hist $=\log (1+\operatorname{sqrt}($ dias_ate_venc $) * .0168) /$ dias_ate_venc ;

$\% \# \#$ feb

pto $=556$;

dias_ate_venc $=9$;

spot=vetor_fx (pto);

janela=63;

volat_hist $=\log (1+\operatorname{sqrt}($ dias_ate_venc $) * .0123) /$ dias_ate_venc;

\%\# DEFINICAO DAS VARIAVEIS UTILIZADAS \#\#\#\#\#\#\#\#\#\#\#\#\#\#\#\#\#\#\#

$\operatorname{dados} \mathrm{P}=$ zeros (dias_ate_venc $* 2+1$,dias_ate_venc);

dados $Q=z e r o s($ dias_ate_venc* $2+1$, dias_ate_venc) ;

dadosP_aux=zeros (dias_ate_venc $* 2+1$, dias_ate_venc) ;

dadosQ_aux=zeros (dias_ate_venc $* 2+1$,dias_ate_venc);

dolfut=zeros (dias_ate_venc,1);

valor_S=zeros (dias_ate_venc $* 2+1$,dias_ate_venc+1);

valor_S_aux $=z e r o s($ dias_ate_venc $* 2+1$,dias_ate_venc +1$)$; 


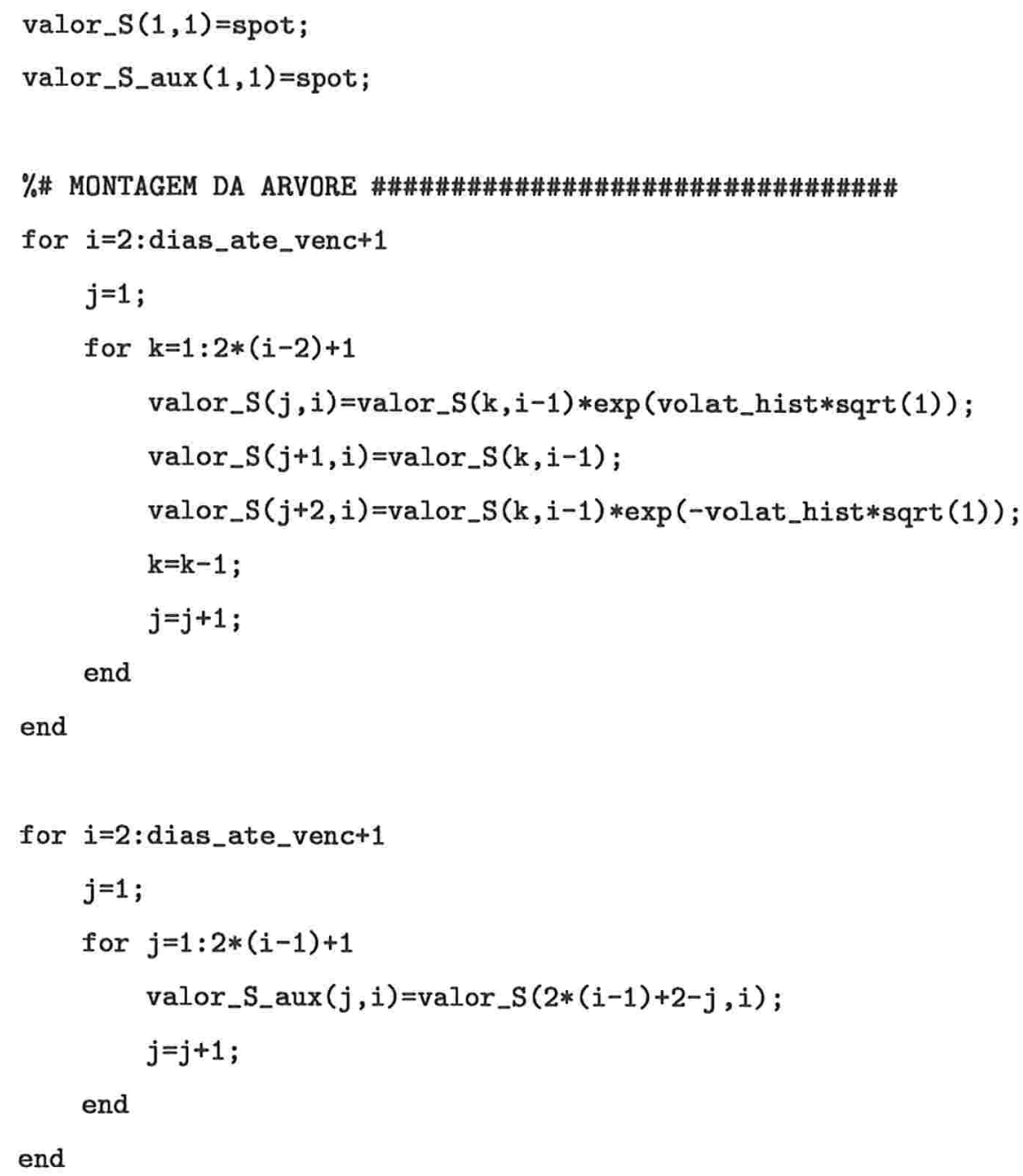

\%\# CALCULO DA DISTRIBUICAO HISTORICA E MINIMIZACAO DA ENTROPIA \#\#\#\#\#\#\#\#\# 
for $i=1$ :dias_ate_venc

bin_hist=zeros $(2 * i+1,1)$;

bin_hist_aux=bin_hist ;

for $j=1: 2 * i+1$

bin_hist_aux $(j)=$ valor_S $(2 * i+2-j, i+1)$;

end

\%\# CALCULO DA DISTRIBUICAO HISTORICA \#\#\#\#\#\#\#\#\#\#\#\#\#\#\#\#\#\#\#\#\#\#\#\#

Distribuicao_P=distribuicao_priori (vetor_fx, pto,i,janela, bin_hist_aux, valor_S_aux);

\%\# CALCULO DO VALOR DE LAMBDA QUE MINIMIZA A ENTROPIA RELATIVA \#\#\#\#\#\#\#\#\#\#\#\#\#\#\#\#\#

MINIMIZA=minimizacao(.5,Distribuicao_P,bin_hist_aux,dolfut (i),i);

Distribuicao_Q=distribuicao_Q(MINIMIZA (1,1), Distribuicao_P,bin_hist_aux,dolfut (i), i);

for $j=1:(2 * i+1)$

$\operatorname{dados} P(j, i)=$ Distribuicao_P $(j)$;

$\operatorname{dados} Q(j, i)=$ Distribuicao_Q $(j)$;

end

end

\%\# DETERMINAÇAO DAS VOLATILIDADES \#\#\#\#\#\#\#\#\#\#\#\#\#\#\#\#\#\#\#\#\#\#\#\#\#

vols=zeros (dias_ate_venc, 1$)$;

paramet=zeros (dias_ate_venc $* 2+1$, dias_ate_venc);

for $i=1$ :dias_ate_venc

$\mathrm{AUX}=0$;

for $j=1: 2 * i+1$

$A U X=A U X+\operatorname{dados} Q(j, i) *\left(\operatorname{valor} \_S \_a u x(j, i+1)-\operatorname{dolfut}(i)\right)^{\sim} 2$; 
end

$\operatorname{vols}(i)=A U X / \operatorname{dolfut}(i)$;

end

\%\# INVERTE A MATRIZ DE PROBABILIDADES PARA FICAR NA ORDEM DOS NOS DA ARVORE \#\#\#

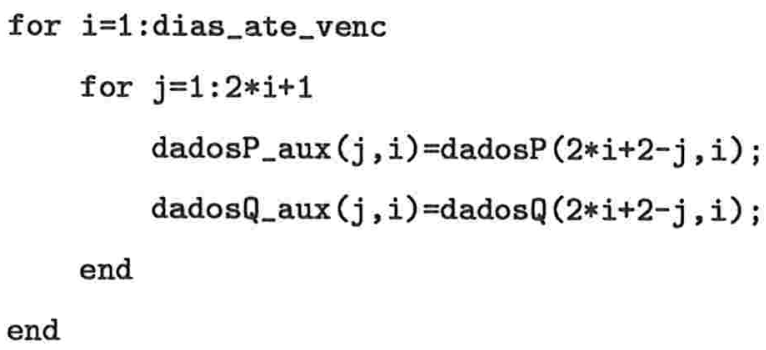

\section{B.2 Programa de Minimização}

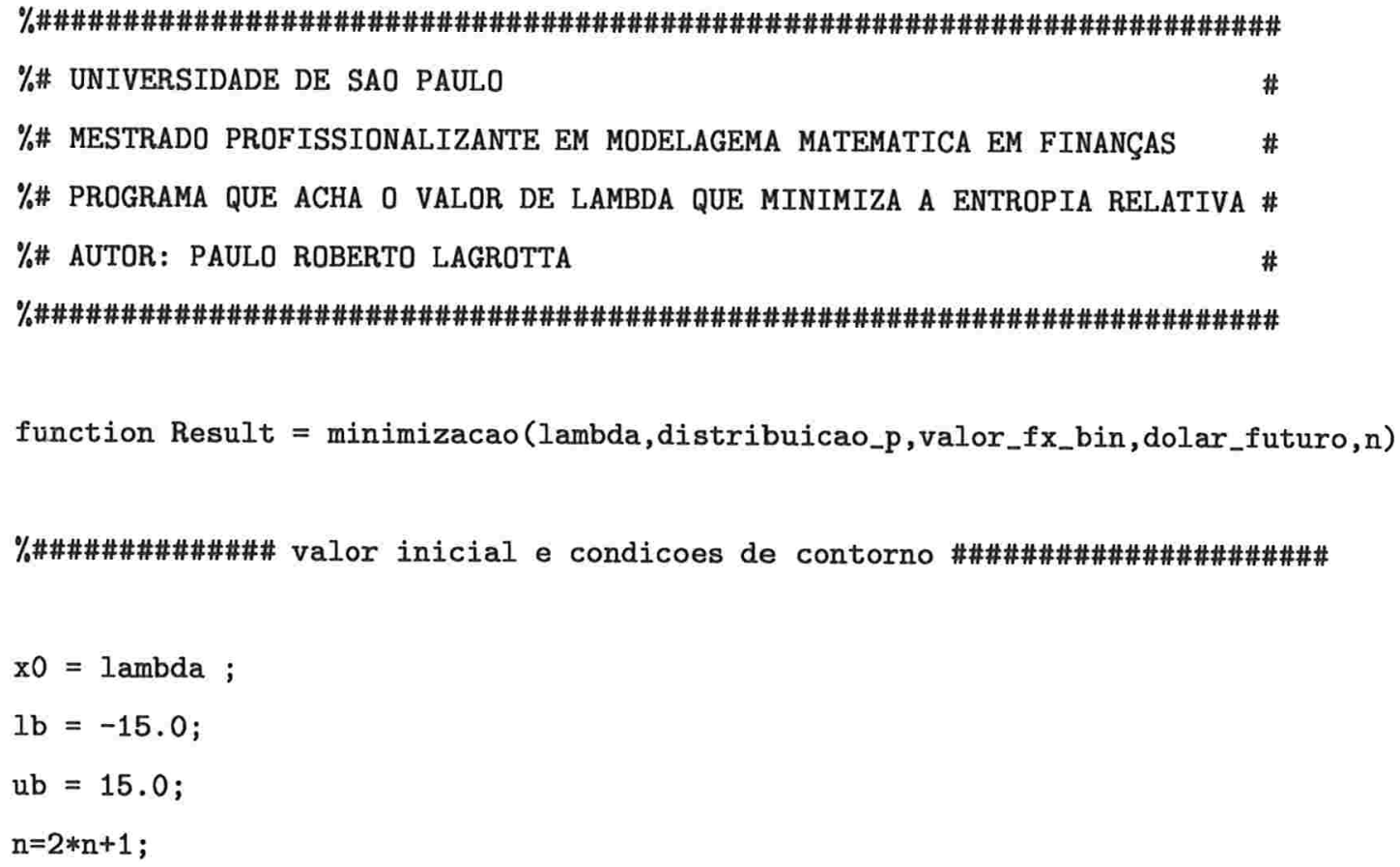




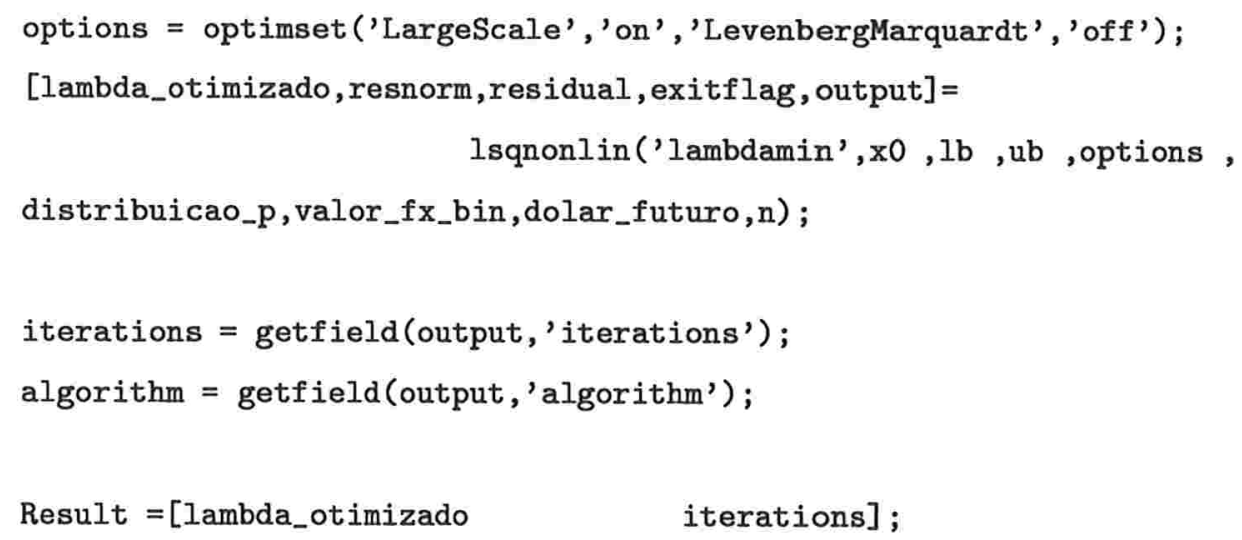

\section{B.3 Programa que Calcula a Distribuição Calibrada Entropicamente}

\%\#\#\#\#\#\#\#\#\#\#\#\#\#\#\#\#\#\#\#\#\#\#\#\#\#\#\#\#\#\#\#\#\#\#\#\#\#\#\#\#\#\#\#\#\#\#\#\#\#\#\#\#\#\#\#\#\#\#\#\#\#\#\#\#

$\% \#$ UNIVERSIDADE DE SAO PAULO

\#

\%\# PROGRAMA QUE CALCULA A DISTRUICAO Q SATISFAZENDO TODAS AS \#

\%\# RESTRICOES E QUE MINIMIZA A ENTROPIA RELATIVA \#

$\% \#$ AUTOR: PAULO ROBERTO LAGROTTA \#

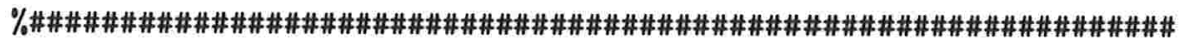

function Result=distribuicao_Q(lambda,distribuicao_p, valor_fx_bin,valor_fx_futuro,n)

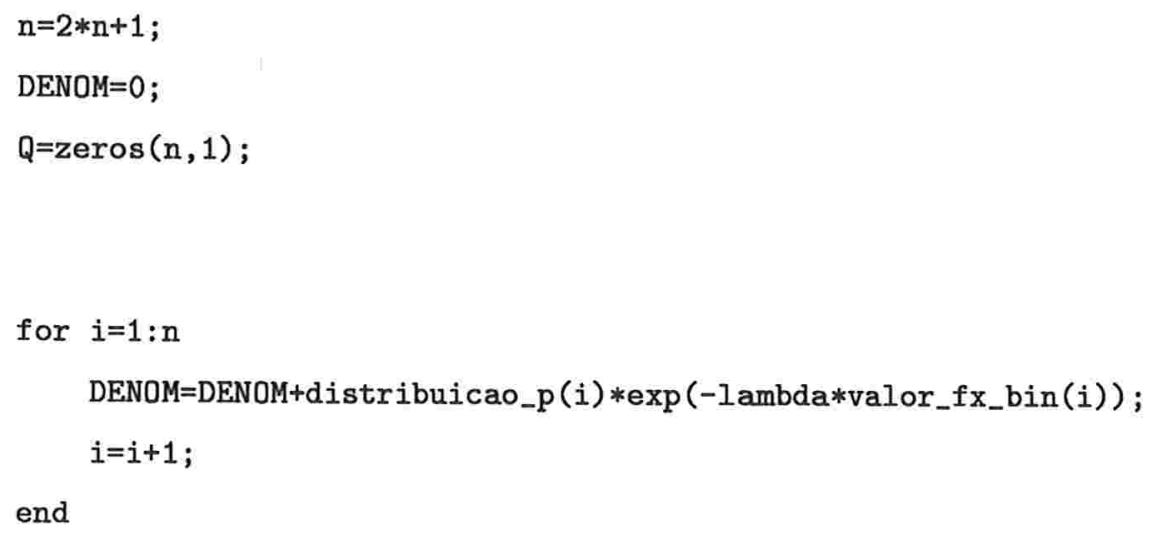




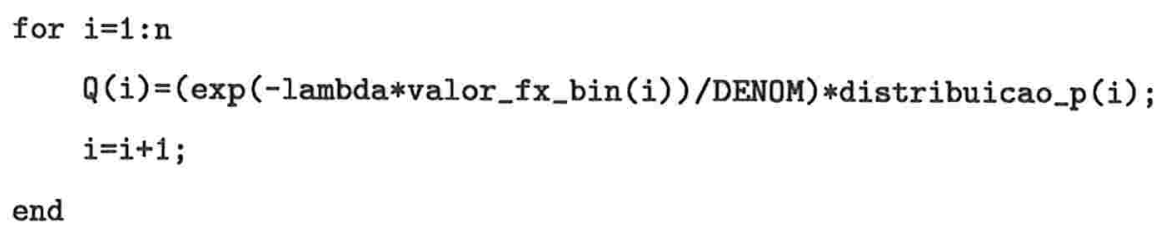

\title{
B.4 Programa que calcula a distribuição histórica
}

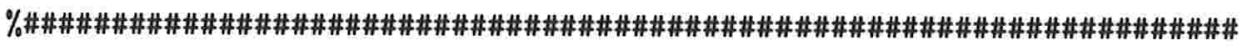 \\ \%\# UNIVERSIDADE DE SAO PAULO \# \\ \%\# MESTRADO PROFISSTONALIZANTE EM MODELAGEMA MATEMATICA EM FINANÇAS \# \\ \%\# PROGRAMA DE CALCULO DA PROBABILIDADE HISTORICA \# \\ \%\# AUTOR: PAULO ROBERTO LAGROTTA \#

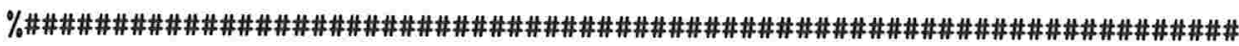

function Result=distribuicao_priori(vetor_fx, posicao_fx,n_dias, janela,bin,valor_S)

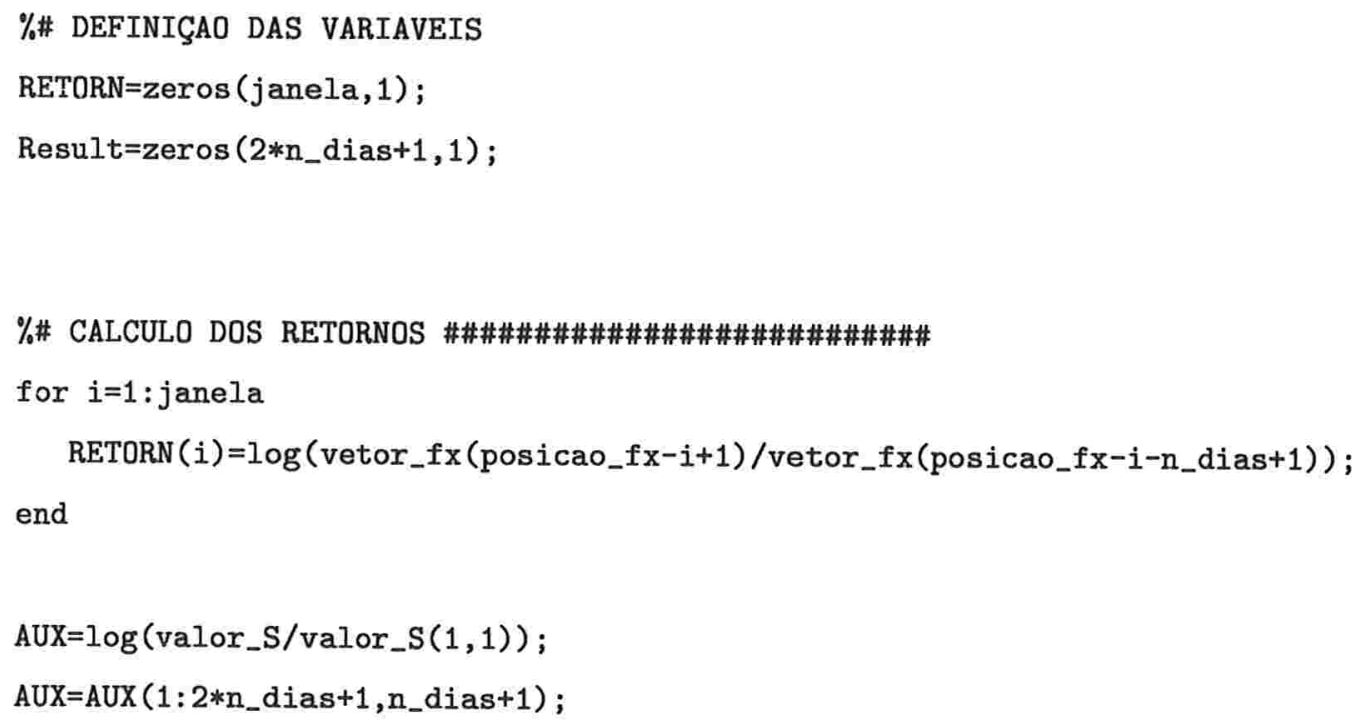


\%\# MONTAGEM DO HISTOGRAMA \#\#\#\#\#\#\#\#\#\#\#\#\#\#\#\#\#\#\#\#\#

$\operatorname{Result}(1)=$ length $(\operatorname{RETORN}(\operatorname{RETORN}<(\operatorname{AUX}(1,1)+\operatorname{AUX}(2,1)) / 2))$;

$\operatorname{Result}\left(2 * n_{\text {_dias }}+1\right)=$ length $\left(\operatorname{RETORN}\left(\operatorname{RETORN}>=\left(\operatorname{AUX}(2 *\right.\right.\right.$ n_dias $)+\operatorname{AUX}\left(2 * \mathrm{n}_{-}\right.$dias +1$\left.\left.\left.)\right) / 2\right)\right)$;

for $i=2: 2 * n \_d i a s$

$\operatorname{Result}(i)=$ length $(\operatorname{RETORN}(\operatorname{RETORN}>=(\operatorname{AUX}(i-1,1)+\operatorname{AUX}(i, 1)) / 2$ \&

$\operatorname{RETORN}<(\operatorname{AUX}(i+1,1)+\operatorname{AUX}(i, 1)) / 2))$;

end

Result=Result $t / j a n e l a ;$ 


\section{Bibliografia}

[1] Avellaneda, M., Friedman, C., Holmes, R., Samperi, D.: Calibrating Volatility Surfaces Via Relative-Entropy Minimization

[2] Rennie, B.: Financial Calculus. An Introduction to derivative pricing, Cambridge, 1996

[3] Callen, H. B.: Thermodynamics and an Introduction to Thermostatistics - Second Edition, Willey, 1985.

[4] Chen, J.:An Entropy Theory of Value,http://papers.ssrn.com/abstract=307442, 2002.

[5] Derman, E., Kani,I., Chriss,N.: Implied Trinomial Trees of the Volatility Smile, 1996.

[6] England, J. W., Martin, N. F. G.: Encyclopedia of Mathematics and its Applications, Addison-Wesley, 1981.

[7] Gulko, L.,: (1998), The Entropy Pricing Theory, PhD Thesis, Yale University.

[8] Hull, J. C.: Opções Futuros e Outros Derivativos, Bolsa de Mercadorias e Futuros (BM\&F), Terceira Edição.

[9] Neftci, S. N.: An Introduction to the Mathematics of Financial Derivatives, Academic Press, Second Edition. 
[10] de Oliveira,G. A., Siqueira, J. de O., e Zimmer, C.: (2001) O Princípio da Mínima Entropia Relativa na Avaliação e Hedging de Opções.

[11] Reza, F. M.: An Introduction to Information Theory, McGraw-Hill Book Company, 1961.

[12] Schirmer, P. P.: Probabilidade e Cálculo Estocástico Aplicados. Um curso Introdutório com ênfase em Finanças, apostila do curso de Mestrado Profissionalizante em Modelagem Matemática, USP.

[13] Siqueira, J. de O.: (1999), Determinação Entrópica do Preço Racional da Opção Européia Simples Ordinária sobre Ação e Bond, Tese de Doutorado, Universidade de São Paulo.

[14] Wilmmot, P., Howison, S., Dewynne, J.: The mathematics of financial derivatives, Cambridge, 1995. 